TITLE:

\title{
Target molecules of food phytochemicals: food science bound for the next dimension.
}

$\operatorname{AUTHOR}(S)$ :

Murakami, Akira; Ohnishi, Kohta

CITATION:

Murakami, Akira ...[et al]. Target molecules of food phytochemicals:

food science bound for the next dimension.. Food \& function 2012, 3(5):

$462-476$

ISSUE DATE:

2012-02-29

URL:

http://hdl.handle.net/2433/172222

RIGHT:

(c) The Royal Society of Chemistry 2012; この論文は出版社版でありませ ん。引用の際には出版社版をご確認ご利用ください。; This is not the published version. Please cite only the published version. 


\title{
Target molecules of food phytochemicals:
}

Food science bound for the next dimension

\author{
Akira Murakami* and Kohta Ohnishi \\ ${ }^{*}$ Division of Food Science and Biotechnology \\ Graduate School of Agriculture \\ Kyoto University, Kyoto 606-8502, JAPAN \\ TEL +81-75-753-6282; FAX +81-75-753-6284; \\ Email: cancer@kais.kyoto-u.ac.jp
}


Phytochemicals are generally defined as secondary metabolites in plants that play crucial roles in their adaptation to a variety of environmental stressors. There is a great body of compelling evidence showing that these metabolites have pronounced potentials for regulating and modulating human health and disease onset as shown by both experimental and epidemiological approaches. Concurrently, enormous efforts have been made to elucidate the mechanism of actions underlying their biological and physiological functions. For example, the pioneering work of Tachibana et al. uncovered the receptor for (-)-epigallocatechin-3-gallate (EGCg) as $67 \mathrm{kDa}$ laminin receptor, which was shown to partially mediate the functions of EGCg such as anti-inflammatory, anti-allergic, and anti-proliferative activities. Thereafter, several protein kinases were identified as binding proteins of flavonoids including myricetin, quercetin, and kaempferol. Isothiocyanates, sulfur-containing phytochemicals present in cruciferous plants, are well known to target Keap1 for activating the transcription factor Nrf2 for inducing self-defensive and anti-oxidative gene expression. In addition, we recently identified CD36 as a cell surface receptor for ursolic acid, a triterpenoid ubiquitously occurring in plants. Importantly, the above mentioned target proteins are indispensable for phytochemicals to exhibit, at least in part, their bioactivities. Nevertheless, it is reasonable to assume that some of the activities and potential toxicities of metabolites are exerted via their interactions with unidentified, off-target proteins. This notion may be supported by the fact that even the rationally designed drugs occasionally display off-target effects and induce unexpected outcomes, including toxicity. Here we update the current status and future directions of research related to target molecules of food phytochemicals. 


\section{Introduction}

In 1993, Swinbanks and O'Brien described the status of development of physiologically functional food in Japan in a column entitled 'Japan explores the boundary between food and medicine' (1). Long before that publication, ancient society had knowledge of medicinal usage of domestic plants as local remedies for injury, epidemic diseases, and other maladies. Even now, traditional herbs and spices are used as surrogate and alternative medicines in many countries.

In nature, plants biosynthesize chemical metabolites, which have diversity in terms of their chemical structures and biological functions. Those are divided into 2 groups of compounds, i.e., primary and secondary metabolites, based on their fundamental roles in plants. The former consist of compounds essential for vital activities, e.g., amino acids, carbohydrates, and lipids, while the latter are biosynthesized to adapt to environmental stressors such as ultraviolet (UV) light, invading microorganisms and insects, and drought. Some secondary metabolites are continuously produced in plants, whereas others are newly formed in accordance with stress signals. Flavonoids are interesting phytochemicals that have versatile biological functions including self-protection from UV light and anti-fungal effects. Similarly, some volatile terpenoids are recognized to serve as sex pheromones or chemical cues for emergency. 'Phytoalexin' is the term used to describe anti-microbial substances synthesized in plants that accumulate rapidly in areas of incompatible pathogen infections. In addition, 'allelopathy' is a biological phenomenon by which plants produce chemicals that influence the growth, survival, and reproduction of other plants. It is also worth noting that amazingly high proportions of the bioactive compounds in foods belong to the group of secondary metabolites, including phytoalexins (2).

As will be discussed in more detail, these secondary metabolites have been shown to have diverse bioactivities in various evaluation systems, ranging from test tube experiments to human intervention studies, while the mechanisms of their actions have been addressed by numerous researchers. 
However, in spite of accumulated mechanistic data, how phytochemicals exhibit physiological functions remains ambiguous and not fully elucidated. This can be easily agreed when comparing with synthetic drugs. Recent remarkable progress in molecular modeling and combinatorial chemistry has enabled chemists to rationally design drugs that display specific interactions with target molecules with high efficacy and fewer side-effects. It is not difficult to dissect their mechanisms of action, because most, if not all, of their targets are already known and these drugs were designed for target proteins at optimized affinity. The goal of this type of pharmacological approach is to confirm their in vivo efficacy in rodent experiments as well as clinical trials (Fig.1).

In contrast, the major approach in the field of food functional science is to first investigate the efficacy of plant extracts or phytochemicals in cellular or animal models, followed by mechanistic studies (Fig.1), as some of the existing mechanistic information is inadequate to fully perceive their mode of actions. For example, if a phytochemical seems to prevent chemical carcinogenesis via suppression of oncogene induction, the question regarding how it suppressed the induction persists. That is, the roles of upstream signaling molecules involved in oncogene induction should further be explored. Furthermore, if an upstream signaling molecule is implicated to play a substantial role, direct inhibition and/or disruption of further upstream signaling molecules must be determined. Identification of the primary targets of phytochemicals is required to gain insight into how they exhibit physiological functions in biological systems. In 2004, Tachibana and coworkers published their excellent work on identification of the receptor for (-)-epigallocatechin-3-gallate (EGCg, Fig. 2) as a $67 \mathrm{kDa}$ laminin receptor (67LR) (3). As noted following, this pioneering work stimulated many other researchers to search for other receptors and binding proteins of EGCg, as well as those of other phytochemicals $(4,5)$, which opened a great window for food science of the next dimension. In this review article, we highlight the molecular targets of food phytochemicals including flavonoids, terpenoids, and sulfur-containing compounds, in discussion of the impact of precise understanding of mechanisms of action. 


\section{Brief overview of typical phytochemicals and their bioactivities}

\section{Polyphenols}

Secondary metabolites can be categorized into several groups based on their chemical structures. For example, flavonoids, one of the largest categories, have a basic carbon skeleton of $\mathrm{C}_{6}-\mathrm{C}_{3}-\mathrm{C}_{6}$ bearing phenolic hydroxyl group(s). Flavonoids are further divided into several subgroups, such as flavones, flavanones, flavonols, catechins, anthocyanins, and others, which differ in regard to the extent of conjugation system, and presence or absence of carbonyl group and hydroxyl group at the 3-position. The most explicit bioactivity of flavonoids may be their antioxidant effects, which are largely dependent on the number of phenolic hydroxyl groups and their locations in a benzene ring. Their potent anti-oxidative activities are broadly attributable to their catechol (1,2-diphenols) and pyrogallol (1,2,3-triphenols) structures. These functional moieties have chemical characteristics to scavenge reactive oxygen species (ROS) through formation of an $o$-benzoquinone counterpart. However, it should be pointed out that they concurrently have pro-oxidative properties, which have some associations with potential toxicity (6), and are dependent on experimental conditions. Another noticeable biochemical activity is modulation of protein functions through interactions between their hydroxyl groups and amino and carbonyl groups in proteins. This allows flavonoids to inhibit or amplify protein functions, leading to phenotypic changes in cells and tissues throughout the body. As an example, flavonoids are distinguished modulators of mitogen-activated protein kinases (MAPKs) (7), which play a variety of decisive roles in the dynamic transducer system by mediating extracellular signals to the nucleus for transcription of adaptive and responsive genes (details are described in a later section). Importantly, such modulations are often related to the mechanisms of onset of many diseases that are considered to be regulated by flavonoids. In fact, quercetin (Fig.2), one of the most well-recognized bioactive flavonoids, has been shown to be a promising cancer 
preventive phytochemical in many rodent experiments (8). Rutin, a quercetin glycoside, attenuated experimental colitis in a mouse model, possibly via the reduction of pro-inflammatory cytokine production (9). Furthermore, green tea catechins have attracted the attention of many investigators because of their multiple physiological activities, including anti-obesity (10), anti-atherosclerosis (11), anti-neurodegenerative (12), and anti-carcinogenesis (13) effects.

\section{Terpenoids}

Terpenoids are biosynthesized in all living organisms via mevalonic acid and methylerythritol 4-phosphate. Biosynthesis of isoprene building units consisting of 5 carbons $\left(\mathrm{C}_{5}\right)$ is the first step in biosynthesis of terpenoids, which are built up through tandem connection of the $\mathrm{C}_{5}$ unit to yield mono- $\left(\mathrm{C}_{5}\right)$, di$\left(C_{10}\right)$, sesqui- $\left(C_{15}\right.$, di- $\left(C_{20}\right)$, sesta- $\left(C_{25}\right)$, and tri- $\left(C_{30}\right)$ terpenes. In addition, carotenoids $\left(\mathrm{C}_{40}\right)$, the most well-known terpenoids, are widely used as pigments and food additives. Although the basic carbon skeleton is subjected to oxidation and hydroxylation, terpenoids are characterized as hydrophobic and lipophilic as compared with polyphenols. As for their physiological functions, the active principles in anti-inflammatory traditional medicines contain various types of terpenoids. As an example, the triterpenoid glycyrrhetinic acid, one of the most well-described phytochemicals, has been demonstrated to have marked anti-inflammatory activities in many experimental models $(14,15)$. Similarly, both oleanolic acid (OA) and ursolic acids (UA) (Fig. 2) have exhibited pronounced anti-inflammatory, anti-oxidative and anti-carcinogenic activities $(16,17)$. Several terpenoids are alternatively known as plant secondary metabolites that serve as phytoalexins. It is notable that insect-inducible monoterpene and sesquiterpene volatiles found in maize and rice have been extensively investigated for their roles as phytoalexins (18).

\section{Sulfur-containing compounds}


Organosulfur phytochemicals such as isothiocyanates (ITCs) as well as those with the di- and tri-sulfide bonds preferentially occur in the Allium and Brassica genera. In those plants, ITCs are biologically dormant in the form of their glucosides, which are collectively termed glucosinolates. Once plants are invaded by insects or microorganisms, myrosinase, a hydrolytic enzyme in vacuoles, reacts with the glucosinolates to release bioactive ITCs, which serve as self-defensive compounds. Most of these phytochemicals are potent inducers of phase II enzymes that play pivotal roles in detoxifying procarcinogens and other toxins by perturbing their biological conversions into ultimate carcinogens (19). Sulforaphane (Fig. 2), the biochemical precursor a substance that is abundantly present in broccoli, has been promoted by many investigators for its substantial ability of inducing phase II enzymes including glutathione S-transferase (GST) and superoxide dismutase (SOD) (20). This efficacy is considered to have close associations with its potent anti-carcinogenesis activities in chemically and biologically induced carcinogenesis in several organs such as the stomach (21), colon (22), and breast (23). On the other hand, phytochemicals possessing di- or tri-sulfide bonds (e.g., diallyl trisulfide, DATS, Fig. 2) are another promising group for cancer prevention and therapy (24), which also have conspicuous potentials to contribute to cardiovascular health. In support of this notion, Yeh et al. demonstrated that supplementation with aged garlic extract, which is rich in those organosulfur compounds, was effective for lowering the plasma concentration of total cholesterol and LDL cholesterol in hypercholesterolemic men as compared with subjects who consumed a placebo (25).

\section{Signal transduction pathways}

\section{General overview}

Extracellular signals are transmitted into cell via complex and well-concerted mechanisms. Figure 3 presents a brief general scheme showing how ligand stimulation produces bioactive proteins in multiple stages. Ligand binding to its 
receptor induces functional activation of receptor-associated adaptors proteins, thereby transmitting signals to numerous downstream molecules, many of which are protein kinases. Mitogen-activated protein kinases (MAPKs), all of which are activated by phosphorylation, are central players that connect extracellular signals to transactivation of target genes (as described below in detail). They basically function downstream of both MAPK kinases (MAPKKs) and MAPK kinases (MAPKKKs). Concurrently, MAPK activation is tightly modulated by MAPK phosphatases (MKPs) (26), the major determinants of which MAPK pathways become dominant. The selectively activated MAPKs, together with other downstream proteins, then induce transactivation of the target genes, which is dependent on transcription factors and their co-activators such as p300 (27). Many pro-inflammatory and oncogenic proteins are regulated by several distinct stages including post-transcription, translation, and post-translation, each of which is triggered at different time points through distinct mechanisms. A large portion of the mRNAs, which have an AU-rich element (ARE) in their 3'-untranslated regions (UTRs), is regulated by post-transcriptional mechanism (28). Also, translation of some cell cycle-regulating and tumor invasive proteins is promoted by mTOR-dependent pathways (29). Post-translation is the most rapid mechanism capable of producing bioactive proteins by one or a few proteolyses of their precursors, which are biologically dormant. This mechanism is well known to function with pro-inflammatory cytokines such as tumor necrosis factor (TNF)- $\alpha$ and interleukin (IL)-1 $\beta$ (30).

\section{Anti-oxidation}

Anti-oxidation can be defined as a fundamental self-defense mechanism that is ubiquitously distributed among organisms. ROS play numerous physiological and pathological roles by oxidizing macro- and micro-components at the molecules, cellular, and tissue levels. It is evident that naturally occurring polyphenols and carotenoids have chemical potentials to remove harmful ROS. 
Importantly, those functions may also have certain connections with their health promotion and disease preventive effects (31-34). The anti-oxidative activities of polyphenols are logically attributable to their catechol structures (termed 'ortho diphenols', Fig. 4A). This functional moiety has a chemical characteristic to scavenge ROS through formation of an o-quinone counterpart (Fig. 4B). In addition, polyphenols with a pyrogallol moiety, which consists of 3 consecutive phenolic hydroxyl groups in a single benzene ring (Fig.4A), are antioxidants superior to the catechol types. In contrast, monophenolic compounds, which essentially cannot be converted into an o-quinone, are far less effective ROS scavengers. Nonetheless, certain phytochemicals including those lacking phenolic groups possess anti-oxidative capacity by up-regulating the induction of anti-oxidant enzymes (20).

The Keap1/Nrf2 system adaptively functions to protect cells from oxidative and electrophilic damages (35). In a normal state, the transcription factor Nrf2 is continuously ubiquitinated by the Cul3-Keap1 ubiquitin E3 ligase complex and thereby rapidly subjected to degradation in proteasomes (Fig. 5). Electrophilic chemicals and oxidative stresses oxidize the reactive cysteine residues of Keap1 in both direct and indirect manners (35). This critical step stabilizes Nrf2, thereby inducing robust expression of a battery of cytoprotective genes, including anti-oxidative genes (glutathione: GSH regeneration, NADPH synthesis, ROS scavenging and quenching), xenobiotic metabolizing genes (L- $\gamma$-glutamyl-L-cysteinyl-glycine: GSH S-transferase (GST), glucuronidase, sulfatase), and protein quality controlling genes (molecular chaperones, ubiquitin/proteasome systems) (35). Prior to translocation of Nrf2 into the nucleus, its transcription activity is modulated by several protein kinases, which are simultaneously activated by stimuli. Feng et al. disclosed that activation of Akt and extracellular signal-regulated kinase (ERK)1/2 is required for OA-induced activation of Nrf2 followed by up-regulation of heme oxygenase (HO)-1 expression in primary rat vascular smooth muscle cells (36). Sauchinone, an antioxidant lignan, protects hepatocytes from acetaminophen toxicity via Nrf2 activation, which is dependent on protein kinase (PKC) $\delta$, 
leading to suppression of glycogen synthase kinase-3 (GSK) $3 \beta$ phosphorylation (37). In addition, protocatechuic acid, a simple phenolic acid as well as the main metabolite of anthocyanins, was found to induce antioxidant genes in J774 A.1 macrophages in a c-Jun-N-terminal kinase (JNK)1/2-mediated and Nrf2-dependent manner (38). As shown in those studies, the functions of protein kinases responsible for Nrf2 activation are dependent on cell type- and types of stimulation. In addition, Nrf2 activity is critically dependent on Bach1, an Nrf2-repressive protein that constitutively binds to the Maf recognition element (39).

Several anti-oxidation enzymes that are Nrf2-dependent and -independent have been reported. For example, SODs, being ubiquitously expressed in cells, are Nrf2-dependent and catalyze the conversion of superoxide anion into molecular oxygen and hydrogen peroxide. They are classified into several isozymes such as cytosolic (or SOD1; Cu/Zn-SODs), mitochondrial (or SOD2; Mn-SOD), and extracellular SOD (or SOD3). Disruption of $\mathrm{Cu} / \mathrm{Zn}$-SODs may be involved in the onset of numerous diseases such as familial amyotrophic lateral sclerosis (40). GSH is the most abundant (0.5 -10 $\mathrm{mM}$ in cells) and functions as an endogenous antioxidant, while its biosynthesis is mediated through Nrf2-dependent $\gamma$-glutamylcysteine synthetase ( $\gamma$-GCS) as well as GSH synthetase. Likewise, selenium-coordinated GSH peroxidase (GPx) is also designated as an Nrf2- and GSH-dependent enzyme that reduces hydroperoxides and lipid peroxides into corresponding alcohols (41) (Fig.6). GPx consists of several subgroups, i.e., cellular GPx (cGPx or GPx1), gastrointestinal GPx (GIGPx or GPx2), extracellular GPx (eGPx, pGPx, GPx3), phospholipid hydroperoxide GPx (PHGPx or GPx4), and selenoprotein $\mathrm{P}$ (SeP or SelP). HO-1 catalyzes the oxidative degradation of heme into biliverdin, carbon monoxide (CO), and $\mathrm{Fe}^{2+}(42)$. Biliverdin is then converted by biliverdin reductase into bilirubin, which is a potent endogenous antioxidant. Thioredoxin (Trx) also acts as a redox sensor protein that is highly susceptible to oxidative stress to form intra-molecular disulfide bonds, thereby reducing oxidized, client proteins (43) (Fig. 6). The Trx family consists of several distinct 
subgroups such as GSH-dependent glutaredoxins (Grx1 in cytosol and Grx2 in mitochondria and nucleus) and protein disulfide isomerase in the endoplasmic reticulum. In addition, peroxiredoxins (Prxs), which are highly expressed in various cellular compartments, is a peroxidase family that reduces intracellular peroxides with the Trx system as the electron donors (Fig. 6). There is an increasing body of evidence showing how oxidative stress triggers activation of Trx systems. In a normal state, $\operatorname{Trx}$ is bound to apoptosis regulating kinase 1 (ASK1), a member of MAPKKK. Oxidation of thiol groups of Trx liberates ASK1 to be associated with TRAF2/6, leading to enhanced phosphorylation of several MAPKs including JNK1/2 and p38 MAPK for apoptosis (44).

\section{Anti-inflammation}

Inflammation is a pathophysiological phenomenon that is involved in an untold number of acute and chronic diseases. Each human organ has the potential for diseases that possess an in inflammatory condition essential to the etiology. A considerable proportion of chronic inflammatory diseases display an overlap with onset and development of cancer, as seen in cases of ulcerative colitis and Crohn's disease (colorectal cancer), reflux esophagitis, Barrett's esophagus (esophageal carcinoma), and hepatitis (hepatocellular carcinoma) (45). Furthermore, inflammation has been recognized to play a pivotal role in insulin resistance, obesity, and diabetes (46) as well as in brain and myocardial infarctions that originate from vascular atherosclerosis (47). Thus, it is considered that regulation of inflammatory conditions provides great benefit for health promotion and disease prevention. In pathogenic conditions, inflammatory responses, which are partly described by immune cell activation, are sustained and exaggerated in a dysregulated manner. Also, genetic alterations are frequently associated with cases of chronic and pathogenic inflammation. For example, in an intriguing study, Kubaszek et al. reported discovery of a promoter polymorphism of the TNF- $\alpha$ (G-308A) gene that confers increased TNF- $\alpha$ production, even though high concentrations of 
inflammatory cytokines are risks for type-2 diabetes (48). In addition, Hwang et al. showed molecular evidence indicating that polymorphisms of IL-1 $\beta$ significantly affect its levels in serum (49).

MAPK signal transduction pathways play several crucial roles in many aspects of immune system-mediated inflammatory responses. MAPKs, which belong to a large family of serine/threonine kinases, constitute major inflammatory signaling pathways from the cell surface to nucleus (50). There are 3 dominant MAPK subfamilies, ERK1/2, p38 MAPK, and JNK1/2, all of which compose an evolutionarily conserved family of enzymes that form a highly integrated network required to achieve specialized cell functions controlling cell differentiation, cell proliferation, and cell death, as well as short-term changes required for homeostasis and acute hormonal responses $(51,52)$. As noted previously, the activities of these MAPKs are modulated by other intracellular enzymes such as MAPKKs, which add a phosphate group to their serine/threonine residue(s). The activities of MAPKKs, in turn, are controlled by MAPKKKs. To date, the enzymes that control MAPKKKs and their substrate specificity are incompletely understood (53). Following the activation of MAPKs, transcription factors present in the cytoplasm or nucleus are phosphorylated and activated, leading to expression of certain target genes for biological responses. Multiple interactions between the different MAPK cascades serve to integrate responses and moderate outputs. Indeed, it has been demonstrated that MAPKs have overlapping substrate specificities and phosphorylation of regulatory sites is shared among multiple protein kinases $(51,54,55)$. Among the 3 major groups of MAPK signaling pathways, the ERK pathway is stimulated mainly by growth factors, mitogens, and tumor promoters $(56,57)$, while those of p38 MAPK and JNK are activated by inflammatory cytokines (IL-1 $\beta$ and TNF- $\alpha$ ), UV light, ROS, heat and osmotic shock, and growth factors $(56,58)$. Inflammatory cytokines are potent triggers of the MAPK pathways, which are often associated with cell growth, differentiation, development, and apoptosis (56,59-62). Therefore, it is

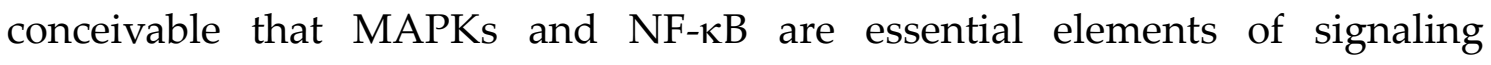


molecules that participate in inflammatory responses.

\section{Molecular targets for phytochemicals}

\section{Polyphenols}

The most commonly recognized binding proteins and target molecules of phytochemicals are flavonoids. Hou and Kumamoto recently published a comprehensive and excellent review describing protein kinases as the targets of flavonoids (7). For the present discussion, we divided naturally occurring polyphenols into several classes and show evidence of their specific target molecules.

\section{Catechins}

As noted above, one of the earliest reports on the specific binding protein of a food phytochemical was published by Tachibana and colleagues who uncovered a receptor for EGCg, 67LR, which was shown to have a $\mathrm{Kd}$ value of $39.9 \mathrm{nM}$ and mediate the EGCg-induced anti-proliferation activity in A549 human lung cancer cells (3). Thereafter, this green tea catechin was also found to target 67LR for disrupting stress fibers and the contractile ring by reducing myosin light chain phosphorylation(63). Along a similar line, 67LR is involved in the EGCg-modulated cytoskeleton in association with its inhibitory activity toward degranulation and suppression of histamine release in KU812 human basophilic cells $(64,65)$, which may account for its anti-allergy activity (66). Additionally, the expression of FceR1, an IgE receptor, was found to be down-regulated by EGCg through its interaction with 67LR (67). Interestingly, a eukaryotic translation initiation factor was identified with direct genetic screening and shown to mediate EGCg-inhibited tumor growth via dephosphorylation of myosin phosphatase by targeting the subunit at Thr-696 in vitro and in vivo $(68,69)$. Moreover, molecular mechanisms underlying the 
anti-inflammatory activity of EGCg may partly be linked to 67LR-mediated down-regulation of toll-like receptor (TLR)2 (70) and TLR4 (71), suggesting counteractive interactions between those cell surface receptors.

Development of new strategies for amplifying the biological functions of EGCg by its combination with other agents may arise from the discovery of 67LR. For example, the combination of EGCg with all-trans retinoic acid (ATRA) led to a conspicuous increase in growth inhibition of B16 mouse melanoma cells (72). In that study, it is interesting that additive or synergistic effects by that combination were seen because ATRA is capable of inducing 67LR. Importantly, the gallate ester group in catechins may be the structural determinant of 67LR binding (3). Meanwhile 67LR was also shown to serve as a receptor for methylated derivatives of EGCg $(73,74)$, which were found present in a unique tea cultivar and have potent anti-allergy activities (75-78). On the other hand, other binding proteins have also been identified as significant molecules that mediate EGCg signaling. For example, Chen et al. confirmed that EGCg is both a substrate and potent inhibitor of catechol-O-methyltransferase (COMT) and either the D- or B-ring of EGCg could induce the substrate binding pocket of this enzyme $(79,80)$. Moreover, vimentin, an intermediate filament protein that has essential roles in cell motility and proliferation, was revealed to be a binding protein of EGCg $(K d=3.3 \mathrm{nM})$ by use of a pull-down assay with Sepharose and proteomics (81). The same research group also reported that both insulin-like growth factor-I receptor (82) and Fyn kinase (83) were direct targets of EGCg and indispensable for its anti-cell transformation activity.

\section{Flavonols}

A common chemical characteristic of flavonols such as myricetin and quercetin is the presence of a hydroxyl group at the 3-position. In addition to ROS scavenging effects, there is ample evidence that a variety of flavonols have specific binding proteins, which accounts for a portion of their diverse biological activities. In recent years, myricetin has been shown to bind several protein kinases, that participate in cellular transformation and proliferation, as 
well as inflammation. For example, Lee and colleagues provided evidence that myricetin (Fig. 2) is a naturally occurring inhibitor of MEK, an upstream signal transducer for both phorbol ester- and EGF-induced neoplastic cell transformation (5). Interestingly, that report showed that this flavonol inhibits H-Ras-induced cell transformation more potently than PD09059, a synthetic MEK inhibitor. Furthermore, though a number of flavonoids are bound to the ATP-binding domain of protein kinases, they found that the mode of MEK inhibition by myricetin may be dissimilar (5). Following that intriguing report, Jung et al. reported that myricetin suppresses UVB-induced skin cancer in mice probably via binding to Fyn kinase, which plays major roles in the expression of cyclooxygenase (COX)-2, an inducible rate-limiting enzyme involved in inflammation (84). Their docking data obtained with computer simulation suggested that it has a high affinity to the ATP-binding site of Fyn, which is located between the $\mathrm{N}$ and $\mathrm{C}$ lobes of the kinase domain. Also, myricetin was reported to suppress UVB-induced wrinkle formation and matrix metalloproteinase (MMP)-9 expression by targeting Raf kinase, which has MEK1/2 as substrates, in an ATP-noncompetitive manner (85). In addition, MKK4, a protein kinase that activates JNK1/2, has been speculated to be the molecular target of myricetin in TNF- $\alpha$-induced vascular endothelial growth factor expression in JB6 P+ mouse epidermal cells (86). Also in that report, myricetin was suggested to target the ATP-binding site of MKK4 based on computer modeling findings (86). Myricetin also binds to Akt to disrupt Akt-mediated activator protein-1 (AP-1) transactivation, cyclin D1 expression, and cell transformation, and molecular modeling results suggested that it binds to the ATP-binding site through hydrogen bonds (87). In another study, ex vivo and in vitro pull-down assays disclosed myricetin binding to JAK1, as well as signal transducers and activators of transcription (STAT)3 (Tyr-705 and Ser-727), but not to epidermal growth factor receptor (EGFR), to inhibit cell transformation in epidermal growth factor (EGF)-activated JB6 cells (88).

Quercetin is one of the most frequently studied flavonoids because of its versatile biological, biochemical, and physiological activities including 
anti-oxidative, anti-inflammatory, and anti-carcinogenesis effects. Like myricetin, quercetin was found to bind to both RAF and MEK1 in a specific fashion for suppressing phorbol ester-induced transformation in JB6 P+ cells (4). Their docking simulation data also implied that quercetin forms a hydrogen bond with the backbone amide group of Ser-212, which is required to stabilize the inactive conformation of the activation loop of MEK1. In addition, PI3K, a protein kinase upstream of Akt/p70S6K/ERK1/2, was shown to be a binding protein for quercetin to disrupt arsenite-induced COX-2 expression in rat liver epithelial cells (89), with similar results seen for kaempferol (Fig. 2), another flavonol analogous to quercetin (90). Isorhamnetin (quercetin 3'-O-methylether) is a naturally occurring flavonoid as well as a quercetin metabolite in biological systems (91-93). A recent report by Kim et al. showed that isorhamnetin directly binds to MEK1 in an ATP-noncompetitive manner and to phosphoinositide-3 kinase (PI3K) in an ATP-competitive manner, leading to distinct attenuation of EGF-induced COX-2 expression in JB6 and A431 human epithelial carcinoma cells (94).

\section{Anthocyanins}

Anthocyanins are flavonoids that are notable as colorants that exhibit a reddish or purple color depending on $\mathrm{pH}$ and the presence or absence of free metal ions. Recently, Kang et al. reported that delphinidin (Fig. 2), a naturally occurring, representative anthocyanin, attenuated phorbol ester-induced neoplastic transformation in JB6 CI41 cells by binding to and inhibiting Raf and MEK1 noncompetitively with ATP, leading to COX-2 down-regulation (95). This pigment was also found to target Fyn kinase for down-regulating TNF- $\alpha$-triggered COX-2 expression in the same cell line (96). Furthermore, cyanidin, another major anthocyanin found in plants, suppressed UVB-induced COX-2 expression by targeting MKK4, MEK1, and Raf1 (97).

\section{Isoflavonoids}

Flavonoids that have a B-ring at the 3-position are categorized as isoflavonoids, 
and are metabolized and/or decomposed in the gastrointestinal tract, especially by microflora (98). Equol (Fig.2), a metabolite of the soybean isoflavone daidzein, targets MEK1 without competing with ATP for reducing the ERK/p90RSK/AP-1 pathway, leading to inhibition of transformation of JB6 cells (99). In addition, Lee et al. found that 7,3',4'-trihydroxyisoflavone, another metabolite of daidzein, inhibited EGF-induced proliferation and transformation of JB6 P+ cells, which may be due to its specific bindings to PI3K and cyclin-dependent kinase (CDK)s, leading to blockade of the Akt/GSK-3b/AP-1 pathway (100). They also demonstrated that this daidzein metabolite suppressed UVB-induced skin carcinogenesis by targeting Cot and MKK4 in an ATP-competing manner (101). Another metabolite of daidzein, 6,7,4'-trihydroxyisoflavone, inhibited proliferation of HCT-116 human colon cancer cells by targeting CDK1/2 in vitro and in vivo (102).

\section{Miscellaneous}

Resveratrol (3,5,4'-trihydroxy-trans-stilbene, Fig.2), a stilbene-type polyphenol, was recently demonstrated to suppress pancreatic cancer by binding LTB4 hydrolase in cultured cells and a xenograft mouse model (103). Meanwhile, a pull-down assay by Kang et al. showed that caffeic acid (3,4-dihydroxycinnamic acid) directly inhibited Fyn kinase, and also attenuated resultant COX-2 expression in JB6 P+ cells and mouse skin (104). Another study found that luteolin (3',4',5,7-tetrahydroxyflavone) inhibited PKC $\varepsilon$ and Src kinase in an ATP-competitive manner, and also decreased UVB-induced tumor incidence, multiplicity, and overall size in SKH hairless mice (105).

\section{Terpenoids}

\section{Ursolic acid}

Both UA and OA have long been recognized to have anti-inflammatory and anti-cancer activities in laboratory animals. In addition, they are also effective for protecting against chemically induced liver injury in laboratory animals 
(106-111). Although the mechanisms by which they suppress inflammation and tumor development are not clear, it has been reported that UA attenuated the expression of inducible nitric oxide synthase (iNOS) and COX-2 expression via $\mathrm{NF \kappa B}$ repression in lipopolysaccharide (LPS) or interferon (IFN)- $\gamma$ activated mouse $\mathrm{M} \phi$ (112). Furthermore, Subbaramaiah K et al. (113) demonstrated that treatment with UA suppressed TPA-mediated induction of COX-2 protein and synthesis of prostaglandin (PG) $\mathrm{E}_{2}$ in human mammary and oral epithelial cells. In a study of its action mechanism, UA suppressed TPA-mediated activation of PKC, ERK1/2, JNK1/2, and p38 MAPK, while it also blocked the binding of AP-1 to the COX-2 promoter (113). These findings are important for understanding the anti-inflammatory properties of UA. In contrast, You et al. (114) reported that UA induced nitric oxide (NO) and TNF- $\alpha$ production via NFאB activation in resting RAW264.7 mouse M $\phi$, implying that the effects of UA on NFKB activities are dependent on the biological status of the target $M \phi$. This background led us to investigate the potential proinflammatory effects of UA in vitro and in vivo as well as the underlying molecular mechanisms. We initially attempted to examine the effects of UA on production of inflammatory cytokines [IL-1 $\beta$, IL-6, TNF- $\alpha$, and MIF (M $\phi$ migration inhibitory factor)] in resting RAW264.7 mouse $\mathrm{M} \phi$ (115). Interestingly, the amount of intracellular MIF protein decreased when the cells were stimulated with UA, which strongly suggests that MIF protein stored in the intracellular compartment is transported and released from cells upon stimulation with this triterpenoid. UA also induced activation of ERK1/2, but not JNK1/2 or p38 MAPK, while the involvement of ERK2 and to a lesser extent ERK1 following activation caused by the release of MIF was revealed in experiments using siRNAs. In addition, in another study, we found that UA markedly increased the protein production of IL-1 $\beta$, IL-6, and MIF, but not of TNF- $\alpha$, in pM $\phi$ from ICR mice (Fig. 7). Also, UA induced intracellular ROS generation with resultant activation of the ERK1/2 and p38 MAPK, but not JNK1/2, pathways. Our data showed that scavenger receptor (SR) CD36 mRNA and protein were expressed in $\mathrm{pM} \phi$ in constitutive manners, while pretreatment of cells with the anti-CD36 antibody significantly 
suppressed IL-1 $\beta$ release and UA bound to CD36 on M $\phi$. Furthermore, the amount of IL-1 $\beta$ released from UA-treated $\mathrm{pM} \phi$ of CD36-deficient mice was markedly lower than from wild-type mice, suggesting that CD36 is one of the membrane receptors of UA, while it remains to be determined whether UA also binds with other SRs or proteins that are involved in IL-1 $\beta$ release. Together, these results suggest that the effects of UA in experiments with RAW264.7 cells may also be mediated by binding to CD36, because it is expressed in a constitutive manner.

\section{Zerumbone}

In 1999, we identified zerumbone (Fig.2), an electrophilic sesquiterpene present in Zingiber zerumbet Smith (shampoo ginger) (Fig.8A), as a potent inhibitor of phorbol ester-induced EB virus activation in Raji cells (116). Thereafter, a number of studies, including ours, demonstrated that it has marked potential for regulating the pathologies of lifestyle-related diseases including cancer and inflammation (117). Oral administration of zerumbone markedly suppressed dextran sulfate sodium-induced colitis in mice (118), as well as azoxymethane-induced formation of aberrant crypt foci (119) and adenomas and adenocarcinomas (120) in rat colons. Interestingly, the anti-cell proliferating activity of zerumbone was found to be cancer- but not normal cell-specific, though the mechanism is not fully understood (121). On the other hand, evidence of its anti-inflammatory and xenobiotic-metabolizing activities have been shown to be related to the major mechanisms of action by which it prevents chemical carcinogenesis. For example, the above-mentioned chemopreventive effects accompanied reductions of $\mathrm{PGE}_{2}$ and COX-2 protein expressions in colonic mucosa (118,120). Using RAW264.7 M demonstrated that zerumbone attenuated COX-2 expression via a post-transcriptional mechanism (122). COX-2 mRNA expression is regulated by at least 3 distinguishable stages in a complex manner. The earliest induction mechanism is related to the finding that COX-2 mRNA contains an ARE in its UTR, which has critical roles for the mRNA stability (123). Several reports of 
different cell types have shown that activation of p38 MAPK leads to stabilization of COX-2 mRNA. Also, a substrate for p38 MAPK, i.e., MAPK-activated protein kinase 2, phosphorylates certain candidate proteins such as HSP27 (124), heterogeneous nuclear ribonucleoprotein A0(125), and Hu antigen $\mathrm{R}$ (HuR) (126), which bind to AREs, thereby contributing to rapid synthesis of COX-2 protein. As noted above, phase II enzymes play central roles in anti-oxidation and detoxification of undesired, harmful chemicals through conjugation reactions. This mechanism participates in anti-carcinogenesis by preventing ultimate carcinogens from their interactions with DNA.

It is important to note that large numbers of such xenobiotic chemicals are subjected to the detoxification system for modulating the expressions of phase I, II, or both types of enzymes in biological systems. We previously reported that zerumbone induced phase II drug-metabolizing enzymes in rat hepatocytes (127). This property was confirmed by following in vivo experiments, in which zerumbone was topically applied to mouse skin to increase the mRNA expression levels of phase II enzymes such as SOD and GPx, whereas those of CYP1A1 and 1B1 were not significantly changed. Meanwhile, we recently generated zerumbone-bound Sepharose gels to explore its binding proteins in vitro (128) (Fig.8B). Incubation of cell lysate from RAW264.7 M $\phi$ with this chemical probe resulted in the identification of HuR and Keap1 as in vitro binding protein of this compound (128). In addition, competitive experiments in that study with zerumbone showed that those bindings are specific, because $\alpha$-humulene, a biologically inactive analogous compound did not show any significant binding competition.

\section{Sulfur-containing compounds}

Organosulfur phytochemicals activate the Keap1/Nrf2 system to provide the host with an amplified self-defense capacity. Sulforaphane (Fig.2), a characteristic constituent of broccoli, prevented chemical carcinogenesis in rodents, and induced phase II enzymes in cell cultures and animal studies (129). 
Hu et al. published a very interesting observation that sulforaphane reacts with at least 4 cysteine residues of Keap1 including C-151 based on mass spectrometry analysis (130). On the other hand, Heiss et al. showed that sulforaphane either reacts with NFkB by binding to essential cysteine residues of p65, or interacts with GSH or other redox regulators like Trx and Ref- 1 , which are relevant for $\mathrm{NF} \kappa \mathrm{B}$ function in $\mathrm{M} \phi$ for exhibiting anti-inflammatory activity (131). In addition, mutation of critical cysteines in the DNA-binding domain of the AP-1 component (Cys-154 in c-Fos and Cys-272 in c-Jun) lead to loss of sensitivity to sulforaphane to inhibit UVB-induced transactivation of AP-1 in HaCaT human keratinocyte (132). It is also worth pointing out that activation of Kea1/Nrf2 is related to its anti-inflammatory activity through repression of the p38 MAPK-dependent pathway $(133,134)$.

Microarray analysis performed by $\mathrm{Hu}$ et al. using Nrf2 knockout mice (-/-) identified Nrf2-dependent, sulforaphane-inducible genes (135). In addition to anti-oxidative and detoxifying enzymes, the identified genes included HSP and ubiquitin/26S proteasome subunits, raising the possibility that this phytochemical affects the protein maintenance control system by up-regulating molecular chaperones and degrading disused proteins. Consistent with this observation, a recent study by Gan et al. showed that sulforaphane treatment remarkably induces HSP27, leading to enhancement of proteasome activity (136). The authors speculated that thiol groups in heat shock factor 1, a key transcription factor for a set of HSPs, might be modified by sulforaphane for its transactivation. Jordit et al. revealed that allyl ITC, the major pungent in mustard oil, mediates its excitatory effects by activating transient receptor potential A1 (TRPA1), a member of the ion channel family, suggesting a cellular and molecular target for the pungent action of mustard oils, and supports the notion of a fundamental role for TRP channels as ionotropic cannabinoid receptors (137). Thereafter, various compounds with an ITC moiety were shown to activate TRPA1 in a manner that relies on covalent modification of cysteine residues within the cytoplasmic $\mathrm{N}$ terminus of the channel (138). Other studies have reported 1'-acetoxychavicol acetate (ACA), a phenyl propanoid in Alpinia 
galanga (great galangal), as a promising cancer preventive agent $(139,140)$, while a more recent report by Narukawa et al. revealed that ACA is a more potent TRPV1 agonist than ally ITC (141). Importantly, one of its chemical characteristics, i.e., electrophilicity due to the exo-methylene group (142), is similar to that of ITC and zerumbone.

Some food stuffs from the Allium genera, which exhibit a particularly pungent aroma, are recognized to contain sulfur-containing compounds such as ITCs and diallyl disulfide (DADS). Bautista et al. found that DATS (Fig.2) directly activates the $\mathrm{Ca}^{2+}$ excitatory ion channel TRPA1 (143). It is tempting to speculate that different plant genera, i.e., Allium and Brassica, have developed evolutionary convergent strategies to target TRPA1 channels on sensory nerve endings to achieve chemical deterrence. On the other hand, treatment with DATS, but not diallyl monosulfide and DADS, led to tubulin polymerization disruption (144). This phenomenon may be mediated by specific oxidative modification of Cys-12 $\beta$ and Cys-354 $\beta$ to form S-allylmercaptocysteine as suggested by peptide mass mapping with liquid chromatography-tandem mass spectrometry analysis (144). It is also important to note that TRPA1 is targeted by a series of $\alpha, \beta$-unsaturated aldehydes (145-148), such as cinnamaldehyde and 4-hydroxy-2-nonenal (HNE). Thus it might be possible that bioactive phytochemicals with similar chemical properties (149), including zerumbone, partially exert their physiological activities through this receptor. Capsaicin, the pungent constituent of chili peppers, binds to and activates transient receptor potential vanilloid 1 (TRPV1) for transducing signals related to pain. Importantly, TRPV1 is not only a prime target for the pharmacological control of pain but also a useful target for drug development to treat various disorders including cardiovascular and gastrointestinal diseases (150). This receptor is a nonselective cation channel with significant permeability to calcium, protons, and large polyvalent cations. TRPV1 is the most polymodal TRP channel, and is activated by numerous stimuli, including heat, voltage, vanilloids, lipids, and protons/cations (151). This receptor also acts as a molecular integrator of physical and chemical stimuli in peripheral nociceptor terminals and plays a 
critical role in thermal inflammatory hyperalgesia (151). TRPV1 binding by capsaicin has drawn the attentions of numerous investigators, because it stimulates lipid catabolism by targeting adipogenesis (152), which is likely associated with the anti-obesity effects of capsaicin. Meanwhile, $\alpha$-lipoic acid (LA), (Fig.2) is a thiol antioxidant distributed in many vegetables, including broccoli and spinach (153). There are multiple lines of in vitro and in vivo evidence that LA is a promising phytochemical for delaying or preventing lifestyle-related diseases such as neurodegenerative disease (154,155), hypertension and nephrotoxicity(156), and type 2 diabetes (157). Also, accumulating evidence has revealed that LA is a striking inducer of the Keap1/Nrf2 system for exhibiting anti-oxidant activity as seen in several cell lines (158-160). In addition, Suh et al. presented impressive findings that, while the functional capability of the Keap1/Nrf2 system declines with aging in rats, i.p. administration with LA considerably attenuated that decay (161).

\section{Do synthetic drugs target only one or multiple biomolecules?}

In contrast to extremely specific bioprobes, such as specific antibodies and oligonucleotides, small molecules have a limited specificity to bind biomolecules. Nonetheless, it is important to note that synthetic drugs exhibit reasonably high binding affinities toward target proteins as compared with natural compounds. This perception is readily justified, because those drugs are designed to optimally fit targets on the basis of data from X-ray analysis of crystallized target proteins and computer docking simulations. It is tempting to speculate that there are significant opportunities for these drugs to have associations with biomolecules other than their intended targets. Celecoxib, a synthetic COX-2 inhibitor, is a representative drug for support of this hypothesis. This agent has been shown to have a conspicuous ability to prevent chemical carcinogenesis in the colons of rodents (162) and a high-risk population (163) by targeting COX-2. On the other hand, using COX-2 deficient mice Pang et al. documented unexpected findings that celecoxib induced apoptosis in gastric cancer cells through a COX-2-unrelated Akt/GSK3ß/NAG-1 
pathway, raising the possibility that it targets functional protein(s) other than COX-2 (164). In parallel, celecoxib reduced the proliferation of COX-2 deficient HCT-15 colon cancer xenografts in nude mice (165). Using a celecoxib analog, Kelp et al. presented findings showing that the 3-phosphoinositide-dependent protein kinase-1(PDK1)/Akt signaling pathway is responsible for the anti-proliferative effects of this agent in prostate cancer cells (166). Moreover, Lev-Ari et al. concluded that the physiological concentration range $(5-10 \mu \mathrm{M})$ of celecoxib is too low to inhibit cancer cell proliferation, and speculated that other target molecule(s) and mechanisms may play a role (167). These unexpected actions of celecoxib may be related to its harmful effect(s). In accordance with this speculation, the potential risk of cardiovascular dysfunctions with celecoxib revealed in clinical studies, may be attributable to its binding to carbonic anhydrase (168). Likewise, nonsteroidal anti-inflammatory drugs (NSAIDs) have been reported to occasionally show their pharmacological activities through COX-independent mechanisms. Kashfi and Rigas found that NSAIDs have multiple targets that include phosphodiesterases, PDK1, peroxisome proliferator-activated receptors, and carbonic anhydrases (169). Along a similar line, the pyridinyl imidazole p38 MAPK inhibitors (SB 203580 and SB 202190) are potent casein kinase 1 inhibitors that block stress-induced CREB phosphorylation at Ser-111, which was importantly found to be p38 MAPK-independent (170). Recently, Xie et al. developed a novel computational strategy to identify protein-ligand binding profiles on a genome wide scale for elucidating the molecular mechanisms associated with the adverse drug effects of cholesteryl ester transfer protein inhibitors, which will help to transform the conventional drug discovery process (single-target/single-drug) to a new paradigm (multi-target/multi-molecule) (171). Overall, researchers should keep in mind that chemical compounds, even highly-selective drugs, have a probability to bind biomolecules in unexpected manners, which may be relevant to their side-effects and/or other concealed physiological activities.

Phytochemicals are believed to have more opportunities for interactions with biological proteins as compared with drugs, based on the fact 
that they are structurally simple. A recent evaluation by Chavez et al. may support this notion, as HNE, a small molecule with an $\alpha, \beta$-unsaturated carbonyl group, was found to covalently bind to multiple house-keeping proteins, including Cys-295 of the tubulin R-1B chain, Cys-351 and Cys-499 in R-actinin-4, Cys-328 of vimentin, Cys-369 of D-3-phosphoglycerate dehydrogenase, and His-246 in aldolase A in THP-1 human monocytes (172). It should be emphasized that there are a number of phytochemicals, including zerumbone and sulforaphane, that have chemical characteristics similar to HNE and their binding manners is presumably non-specific like HNE, rather than specific. Interestingly, the food colorant erythrosine B perturbed multiple interactions between tumor necrosis factor superfamily members and their corresponding receptors (TNF-R-TNF $\alpha$, CD40-CD154, BAFF-R-BAFF, RANK-RANKL, OX40-OX40L, 4-1BB-4-1BBL, EGF-R-EGF) (173), which shows the possibility that multiple interactions of natural products can be positively evaluated. Also, the major tissue component extracellular matrix, was modified by small-molecules via multiple bindings, which may be associated with cell cycle regulation $(174)(81,144)$.

It has been shown that phytochemicals bind to specific receptors and proteins for exhibiting biological and physiological activities. On the other hand, few studies have investigated their non-specific bindings, which might be related to potential side-effects, have some beneficial effects, or had no effects. To date, no method is available to quantify the non-specific interactions between ligands and biomolecules. However, McLure et al. investigated the non-specific bindings of synthetic drugs by incubating human liver microsomes with 1-anilinonaphthalene-8-sulfonate (175), a fluorescence agent. This experimental method may be advantageous for safety assessment and prediction of unwanted side-effects.

\section{Phytochemicals are not originally produced for human use}

Most, if not all, of plant secondary metabolites are biosynthesized for the purpose of self-defense and adaptation to environmental stresses. For example, 
polyphenols are produced for protection against sunlight-induced oxidative damages, while bactericidal and insecticidal phytochemicals serve as 'chemical weapons' that combat invading organisms (Fig. 9). Indeed, it is reasonable to speculate that antioxidants play beneficial roles in both plants and humans by scavenging harmful ROS. On the other hand, it is logically puzzling that the defensive chemicals produced in plants also exhibit health promotion and disease preventive effects in experimental animals and humans. One clue is related to the fact that phytochemicals essentially function as non-nutrients and xenobiotics in humans, which is supported by the findings showed that the bioavailability of polyphenols, for example, is very poor and they are immediately subjected to biological conjugation systems for rapid excretion. Moreover, it is very important to note that most of those metabolic conversions dramatically reduce their biological activities (176-178). In addition, the exclusion mechanisms of phytochemicals have partial associations with those of hazardous toxins $(179,180)$, while they are in contrast to those of nutrients $(181,182)$, vitamins $(183,184)$ and minerals $(185,186)$, most of which are actively incorporated via specific receptors and transporters. Interestingly, Son et al. presented the idea that phytochemicals exert hormetic effects on animals (187).

'Hormesis' is a physiological mechanism by which sub-toxic doses of physical, chemical, or biological stressors trigger the adaptive mechanism to protect from subsequent more severe stresses, though an overdose results in catastrophe, as shown by U-shaped dose responses (187). Thus, mild stress from exposure to xenobiotics generates positive effects for health promotion and disease prevention by adaptive up-regulation of self-defense systems. Alcohol consumption is a practical example to describe hormesis since low and medium levels of intake, in general, actually promote health (188). Although the mechanism is not fully understood, alcohol consumption-induced elevation of alcohol and aldehyde dehydrogenases (189) may be protective against environmental aldehyde toxins. It is of magnitude importance to indicate that hormesis by chemical exposure has some convergence with that by dietary energy restriction (190) and exercise (191), both of which definitively contribute 
to longevity and health promotion.

\section{Conclusion}

Both endogenous and exogenous electrophiles in subtoxic doses elevate detoxifying activity via the Keap1/Nrf2 system, which promotes their excretion by glutathionylation. Exposure of skin to moderate UVB light also activates this protective system, leading to mitigation of oxidative skin damage (192). Together, a wide variety of environmental stressors stimulates human self-defensive systems for adaptation. When the stress burden is beyond capacity, severe damage and toxicity become dominant, and occasionally lethal (Fig. 10). Recent reports of the side-effects of supplements especially at high doses (193-195) may reflect an imbalance between chemical stress and capacity. Identification of the target molecules of phytochemicals currently occupies a significant portion of research in the field of food functional science. Such a direction is challenging, though it will lead to not only a better understanding of the mechanisms of action but also to more precise assessment of side-effects and potential toxicity.

Molecular-targeted food functional science investigations may generate powerful strategies with combinations of phytochemicals and/or synthetic drugs for synergistic efficacy. Noticeable differences between phytochemicals and drugs can be seen in their target specificity. The broad range of target binding properties of the former may be associated with their 'mild' bioactivities as compared to rationally designed drugs, while their non-specific or 'dirty' bindings have no significant involvement with the mechanisms of potential toxicity. Alternatively, their broad range of bindings to biological proteins might lead to some hormetic effects, thus potentiating the capability of self-defense systems. Therefore, the putative non-target effects of phytochemicals, which are largely absent in drugs, may exhibit significant activity and should be explored in detail in future studies. 


\section{Acknowledgements}

The authors thank Profs. Hajime Ohigashi (Fukui Prefectural University) and Koichi Koshimizu (Professor emeritus, Kyoto University) for their exellent supervision over the years. We are also grateful for our collaborators, as well as the previous and current graduate students in our lab, especially Dr. Yasutaka Ikeda. Our studies described in this review were partly supported by a Grant-in Aid for Scientific Research (C) (A.M.) and a grant from the the Japan Society for the Promotion of Science Fellows (K.O.).

\section{Abbreviations}

AP-1

ARE

ASK1

ATRA

AUF-1

CDK

$\mathrm{CO}$

COMT

DADS

DATS

EGCg

EGF

EGFR

ERK

iNOS

JNK

GCS

GPx

GSK3b activator protein-1

AU-rich element

apoptosis regulating kinase 1

all-trans retinoic acid

AU-rich element/poly(U)-binding/degradation factor-1

cyclin-dependent kinase

carbon monoxide

catechol-O-methyltransferase

diallyl disulfide

diallyl trisulfide

(-)-epigallocatechin-3-gallate

epidermal growth factor

epidermal growth factor receptor

extracellular signal-regulated kinase

inducible nitric oxide synthase

c-Jun-N-terminal kinase

glutamylcysteine synthetase

GSH peroxidase

glycogen synthase kinase-3b 
GSH

GST

HNE

HSP

$\mathrm{HO}$

HuR

IL

ITC

LA

LPS

MAPK

MAPKK/MEK/MKK

MAPKKK

$\mathrm{M} \phi$

MIF

MKP

MMP

NF

NO

NSAIDs

$\mathrm{OA}$

PDK-1

PG

PI3K

$\mathrm{pM} \phi$

PKC

Prx

ROS

SeP

SOD

STAT glutathione

glutathione $S$-transferase

4-hydroxy-2-nonenal

heat shock proteins

heme oxygenase

Hu antigen $R$

interleukin

isothiocyanate

$\alpha$-lipoic acid

lipopolysaccharide

mitogen-activated protein kinase

MAPK kinase

MAPK kinase kinase

macrophages

$\mathrm{M} \phi$ migration inhibitory factor

MAPK phosphatases

matrix metalloproteinase

nuclear factor

nitric oxide

anti-inflammatory drugs

oleanolic acid

3-phosphoinositide-dependent protein kinase-1

prostaglandin

phosphoinositide-3 kinase

peritoneal $\mathrm{M} \phi$

protein kinase

peroxiredoxin

reactive oxygen species

selenoprotein $\mathrm{P}$

superoxide dismutase

signal transducers and activators of transcription 
TLR

TNF

TRPA1

$\operatorname{Tr} x$

UA

UB

UTR

67LR toll-like receptor

tumor necrosis factor

transient receptor potential A1

thioredoxin

ursolic acid

ultraviolet

untranslated region

$67 \mathrm{kDa}$ laminin receptor 


\section{References}

1. Swinbanks, D., and O'Brien, J. (1993) Nature 364, 180

2. Boue, S. M., Cleveland, T. E., Carter-Wientjes, C., Shih, B. Y., Bhatnagar, D., McLachlan, J. M., and Burow, M. E. (2009) JAgric Food Chem 57, 2614-2622

3. Tachibana, H., Koga, K., Fujimura, Y., and Yamada, K. (2004) Nat Struct Mol Biol 11, 380-381

4. Lee, K. W., Kang, N. J., Heo, Y. S., Rogozin, E. A., Pugliese, A., Hwang, M. K., Bowden, G. T., Bode, A. M., Lee, H. J., and Dong, Z. (2008) Cancer Res 68, 946-955

5. $\quad$ Lee, K. W., Kang, N. J., Rogozin, E. A., Kim, H. G., Cho, Y. Y., Bode, A. M., Lee, H. J., Surh, Y. J., Bowden, G. T., and Dong, Z. (2007) Carcinogenesis 28, 1918-1927

6. Schweigert, N., Zehnder, A. J., and Eggen, R. I. (2001) Environ Microbiol 3, 81-91

7. Hou, D. X., and Kumamoto, T. (2010) Antioxid Redox Signal 13, 691-719

8. Murakami, A., Ashida, H., and Terao, J. (2008) Cancer Lett 269, 315-325

9. Kwon, K. H., Murakami, A., Tanaka, T., and Ohigashi, H. (2005) Biochem Pharmacol 69, 395-406

10. Rains, T. M., Agarwal, S., and Maki, K. C. (2011) J Nutr Biochem 22, 1-7

11. Moore, R. J., Jackson, K. G., and Minihane, A. M. (2009) Br J Nutr 102, 1790-1802

12. Mandel, S., and Youdim, M. B. (2004) Free Radic Biol Med 37, 304-317

13. Yang, C. S., Wang, X., Lu, G., and Picinich, S. C. (2009) Nat Rev Cancer 9, 429-439

14. Kao, T. C., Shyu, M. H., and Yen, G. C. (2010) J Agric Food Chem 58, 8623-8629

15. Chang, Y. L., Chen, C. L., Kuo, C. L., Chen, B. C., and You, J. S. (2010) Acta Pharmacol Sin 31, 546-553

16. Tsai, S. J., and Yin, M. C. (2008) J Food Sci 73, H174-178

17. Shyu, M. H., Kao, T. C., and Yen, G. C. (2010) JAgric Food Chem 58, 6110-6118

18. Schmelz, E. A., Kaplan, F., Huffaker, A., Dafoe, N. J., Vaughan, M. M., Ni, X., Rocca, J. R., Alborn, H. T., and Teal, P. E. (2011) Proc Natl Acad Sci U S A 108, 5455-5460

19. Nakamura, Y., and Miyoshi, N. (2010) Biosci Biotechnol Biochem 74, 242-255

20. Zhang, Y., Talalay, P., Cho, C. G., and Posner, G. H. (1992) Proc Natl Acad Sci U S A 89, 2399-2403

21. Fahey, J. W., Haristoy, X., Dolan, P. M., Kensler, T. W., Scholtus, I., Stephenson, K. K., Talalay, P., and Lozniewski, A. (2002) Proc Natl Acad Sci U SA 99, 7610-7615

22. Chung, F. L., Conaway, C. C., Rao, C. V., and Reddy, B. S. (2000) Carcinogenesis 21, 2287-2291

23. Cornblatt, B. S., Ye, L., Dinkova-Kostova, A. T., Erb, M., Fahey, J. W., Singh, N. K., Chen, M. S., Stierer, T., Garrett-Mayer, E., Argani, P., Davidson, N. E., Talalay, P., 
Kensler, T. W., and Visvanathan, K. (2007) Carcinogenesis 28, 1485-1490

24. Powolny, A. A., and Singh, S. V. (2008) Cancer Lett 269, 305-314

25. Yeh, Y. Y., and Liu, L. (2001) J Nutr 131, 989S-993S

26. Farooq, A., and Zhou, M. M. (2004) Cell Signal 16, 769-779

27. Eckner, R. (1996) Biol Chem 377, 685-688

28. Chen, C. Y., and Shyu, A. B. (1995) Trends Biochem Sci 20, 465-470

29. Gingras, A. C., Raught, B., and Sonenberg, N. (2004) Curr Top Microbiol Immunol 279, 169-197

30. Le, G. T., and Abbenante, G. (2005) Curr Med Chem 12, 2963-2977

31. Shih, C. K., Chang, J. H., Yang, S. H., Chou, T. W., and Cheng, H. H. (2008) Br J Nutr 99, 59-66

32. Agarwal, A., Shen, H., Agarwal, S., and Rao, A. V. (2001) J Med Food 4, 9-15

33. Frei, B., and Higdon, J. V. (2003) J Nutr 133, 3275S-3284S

34. Raederstorff, D. (2009) Int J Vitam Nutr Res 79, 152-165

35. Kobayashi, M., and Yamamoto, M. (2005) Antioxid Redox Signal 7, 385-394

36. Feng, J., Zhang, P., Chen, X., and He, G. (2011) J Cell Biochem 112, 1524-1531

37. Kay, H. Y., Kim, Y. W., Lee, D. H., Sung, S. H., Hwang, S. J., and Kim, S. G. (2010) Br J Pharmacol

38. Varì, R., D'Archivio, M., Filesi, C., Carotenuto, S., Scazzocchio, B., Santangelo, C., Giovannini, C., and Masella, R. (2011) J Nutr Biochem 22, 409-417

39. Sun, J., Brand, M., Zenke, Y., Tashiro, S., Groudine, M., and Igarashi, K. (2004) Proc Natl Acad Sci USA 101, 1461-1466

40. Liochev, S. I., and Fridovich, I. (2003) Free Radic Biol Med 34, 1383-1389

41. Brigelius-Flohé, R. (2006) Biol Chem 387, 1329-1335

42. Tyrrell, R. (1999) Free Radic Res 31, 335-340

43. Powis, G., Mustacich, D., and Coon, A. (2000) Free Radic Biol Med 29, 312-322

44. Fujino, G., Noguchi, T., Matsuzawa, A., Yamauchi, S., Saitoh, M., Takeda, K., and Ichijo, H. (2007) Mol Cell Biol 27, 8152-8163

45. Coussens, L. M., and Werb, Z. (2002) Nature 420, 860-867

46. Dandona, P., Aljada, A., and Bandyopadhyay, A. (2004) Trends Immunol 25, 4-7

47. Libby, P., and Ridker, P. M. (2004) Am J Med 116 Suppl 6A, 9S-16S

48. Kubaszek, A., Pihlajamäki, J., Komarovski, V., Lindi, V., Lindström, J., Eriksson, J., Valle, T. T., Hämäläinen, H., Ilanne-Parikka, P., Keinänen-Kiukaanniemi, S., Tuomilehto, J., Uusitupa, M., Laakso, M., and Study, F. D. P. (2003) Diabetes 52, $1872-1876$

49. Hwang, I. R., Kodama, T., Kikuchi, S., Sakai, K., Peterson, L. E., Graham, D. Y., and 
Yamaoka, Y. (2002) Gastroenterology 123, 1793-1803

50. Dong, C., Davis, R. J., and Flavell, R. A. (2002) Annu Rev Immunol 20, 55-72

51. Lewis, T. S., Shapiro, P. S., and Ahn, N. G. (1998) Adv Cancer Res 74, 49-139

52. Kyriakis, J. M., and Avruch, J. (2001) Physiol Rev 81, 807-869

53. Cobb, M. H., Xu, S., Hepler, J. E., Hutchison, M., Frost, J., and Robbins, D. J. (1994) Cell Mol Biol Res 40, 253-256

54. Fukunaga, R., and Hunter, T. (1997) EMBO J 16, 1921-1933

55. Waskiewicz, A. J., Flynn, A., Proud, C. G., and Cooper, J. A. (1997) EMBO J 16, 1909-1920

56. Robinson, M. J., and Cobb, M. H. (1997) Curr Opin Cell Biol 9, 180-186

57. Lee, J. T., and McCubrey, J. A. (2002) Leukemia 16, 486-507

58. Ono, K., and Han, J. (2000) Cell Signal 12, 1-13

59. Hsu, H. Y., Hua, K. F., Lin, C. C., Lin, C. H., Hsu, J., and Wong, C. H. (2004) $J$ Immunol 173, 5989-5999

60. Shi, L., Kishore, R., McMullen, M. R., and Nagy, L. E. (2002) Am J Physiol Cell Physiol 282, C1205-1211

61. Díaz-Rodríguez, E., Montero, J. C., Esparís-Ogando, A., Yuste, L., and Pandiella, A. (2002) Mol Biol Cell 13, 2031-2044

62. Zheng, Y., Schlondorff, J., and Blobel, C. P. (2002) J Biol Chem 277, 42463-42470

63. Umeda, D., Tachibana, H., and Yamada, K. (2005) Biochem Biophys Res Commun $333,628-635$

64. Fujimura, Y., Umeda, D., Kiyohara, Y., Sunada, Y., Yamada, K., and Tachibana, H. (2006) Biochem Biophys Res Commun 348, 524-531

65. Fujimura, Y., Umeda, D., Yamada, K., and Tachibana, H. (2008) Arch Biochem Biophys 476, 133-138

66. Suzuki, M., Yoshino, K., Maeda-Yamamoto, M., Miyase, T., and Sano, M. (2000) $J$ Agric Food Chem 48, 5649-5653

67. Fujimura, Y., Yamada, K., and Tachibana, H. (2005) Biochem Biophys Res Commun 336, $674-681$

68. Umeda, D., Yano, S., Yamada, K., and Tachibana, H. (2008) J Biol Chem 283, 3050-3058

69. Umeda, D., Yano, S., Yamada, K., and Tachibana, H. (2008) Biochem Biophys Res Commun 371, 172-176

70. Byun, E. H., Omura, T., Yamada, K., and Tachibana, H. (2011) FEBS Lett 585, 814-820

71. Hong Byun, E., Fujimura, Y., Yamada, K., and Tachibana, H. (2010) J Immunol 185, 
$33-45$

72. Lee, J. H., Kishikawa, M., Kumazoe, M., Yamada, K., and Tachibana, H. (2010) PLoS One 5, e11051

73. Fujimura, Y., Umeda, D., Yano, S., Maeda-Yamamoto, M., Yamada, K., and Tachibana, H. (2007) Biochem Biophys Res Commun 364, 79-85

74. Yano, S., Fujimura, Y., Umeda, D., Miyase, T., Yamada, K., and Tachibana, H. (2007) JAgric Food Chem 55, 7144-7148

75. Kurita, I., Maeda-Yamamoto, M., Tachibana, H., and Kamei, M. (2010) J Agric Food Chem 58, 1903-1908

76. Maeda-Yamamoto, M., Ema, K., and Shibuichi, I. (2007) Cytotechnology 55, 135-142

77. Maeda-Yamamoto, M., Ema, K., Monobe, M., Shibuichi, I., Shinoda, Y., Yamamoto, T., and Fujisawa, T. (2009) Allergol Int 58, 437-444

78. Maeda-Yamamoto, M., Ema, K., Tokuda, Y., Monobe, M., Tachibana, H., Sameshima, Y., and Kuriyama, S. (2011) Cytotechnology 63, 171-179

79. Chen, D., Wang, C. Y., Lambert, J. D., Ai, N., Welsh, W. J., and Yang, C. S. (2005) Biochem Pharmacol 69, 1523-1531

80. Zhu, B. T., Shim, J. Y., Nagai, M., and Bai, H. W. (2008) Xenobiotica 38, 130-146

81. Ermakova, S., Choi, B. Y., Choi, H. S., Kang, B. S., Bode, A. M., and Dong, Z. (2005) $J$ Biol Chem 280, 16882-16890

82. Li, M., He, Z., Ermakova, S., Zheng, D., Tang, F., Cho, Y. Y., Zhu, F., Ma, W. Y., Sham, Y., Rogozin, E. A., Bode, A. M., Cao, Y., and Dong, Z. (2007) Cancer Epidemiol Biomarkers Prev 16, 598-605

83. He, Z., Tang, F., Ermakova, S., Li, M., Zhao, Q., Cho, Y. Y., Ma, W. Y., Choi, H. S., Bode, A. M., Yang, C. S., and Dong, Z. (2008) Mol Carcinog 47, 172-183

84. Jung, S. K., Lee, K. W., Byun, S., Kang, N. J., Lim, S. H., Heo, Y. S., Bode, A. M., Bowden, G. T., Lee, H. J., and Dong, Z. (2008) Cancer Res 68, 6021-6029

85. Jung, S. K., Lee, K. W., Kim, H. Y., Oh, M. H., Byun, S., Lim, S. H., Heo, Y. S., Kang, N. J., Bode, A. M., Dong, Z., and Lee, H. J. (2010) Biochem Pharmacol 79, 1455-1461

86. Kim, J. E., Kwon, J. Y., Lee, D. E., Kang, N. J., Heo, Y. S., Lee, K. W., and Lee, H. J. (2009) Biochem Pharmacol 77, 412-421

87. Kumamoto, T., Fujii, M., and Hou, D. X. (2009) Mol Cell Biochem 332, 33-41

88. Kumamoto, T., Fujii, M., and Hou, D. X. (2009) Cancer Lett 275, 17-26

89. Lee, K. M., Hwang, M. K., Lee, D. E., Lee, K. W., and Lee, H. J. (2010) J Agric Food Chem 58, 5815-5820

90. Lee, K. M., Lee, D. E., Seo, S. K., Hwang, M. K., Heo, Y. S., Lee, K. W., and Lee, H. J. (2010) Carcinogenesis 31, 1338-1343 
91. Mullen, W., Edwards, C. A., and Crozier, A. (2006) Br J Nutr 96, 107-116

92. Boulton, D. W., Walle, U. K., and Walle, T. (1999) J Pharm Pharmacol 51, 353-359

93. Ibarra, M., Moreno, L., Vera, R., Cogolludo, A., Duarte, J., Tamargo, J., and Perez-Vizcaino, F. (2003) Planta Med 69, 995-1000

94. Kim, J. E., Lee, D. E., Lee, K. W., Son, J. E., Seo, S. K., Li, J., Jung, S. K., Heo, Y. S., Mottamal, M., Bode, A. M., Dong, Z., and Lee, H. J. (2011) Cancer Prev Res (Phila) 4, 582-591

95. Kang, N. J., Lee, K. W., Kwon, J. Y., Hwang, M. K., Rogozin, E. A., Heo, Y. S., Bode, A. M., Lee, H. J., and Dong, Z. (2008) Cancer Prev Res (Phila) 1, 522-531

96. Hwang, M. K., Kang, N. J., Heo, Y. S., Lee, K. W., and Lee, H. J. (2009) Biochem Pharmacol 77, 1213-1222

97. Kim, J. E., Kwon, J. Y., Seo, S. K., Son, J. E., Jung, S. K., Min, S. Y., Hwang, M. K., Heo, Y. S., Lee, K. W., and Lee, H. J. (2010) Biochem Pharmacol 79, 1473-1482

98. Yuan, J. P., Wang, J. H., and Liu, X. (2007) Mol Nutr Food Res 51, 765-781

99. Kang, N. J., Lee, K. W., Rogozin, E. A., Cho, Y. Y., Heo, Y. S., Bode, A. M., Lee, H. J., and Dong, Z. (2007) J Biol Chem 282, 32856-32866

100. Lee, D. E., Lee, K. W., Song, N. R., Seo, S. K., Heo, Y. S., Kang, N. J., Bode, A. M., Lee, H. J., and Dong, Z. (2010) J Biol Chem 285, 21458-21466

101. Lee, D. E., Lee, K. W., Byun, S., Jung, S. K., Song, N., Lim, S. H., Heo, Y. S., Kim, J. E., Kang, N. J., Kim, B. Y., Bowden, G. T., Bode, A. M., Lee, H. J., and Dong, Z. (2011) J Biol Chem 286, 14246-14256

102. Lee, D. E., Lee, K. W., Jung, S. K., Lee, E. J., Hwang, J. A., Lim, T. G., Kim, B. Y., Bode, A. M., Lee, H. J., and Dong, Z. (2011) Carcinogenesis 32, 629-635

103. Oi, N., Jeong, C. H., Nadas, J., Cho, Y. Y., Pugliese, A., Bode, A. M., and Dong, Z. (2010) Cancer Res 70, 9755-9764

104. Kang, N. J., Lee, K. W., Shin, B. J., Jung, S. K., Hwang, M. K., Bode, A. M., Heo, Y. S., Lee, H. J., and Dong, Z. (2009) Carcinogenesis 30, 321-330

105. Byun, S., Lee, K. W., Jung, S. K., Lee, E. J., Hwang, M. K., Lim, S. H., Bode, A. M., Lee, H. J., and Dong, Z. (2010) Cancer Res 70, 2415-2423

106. Kosuge, T., Yokota, M., Sugiyama, K., Yamamoto, T., Mure, T., and Yamazawa, H. (1985) Chem Pharm Bull (Tokyo) 33, 5351-5354

107. Gupta, M. B., Bhalla, T. N., Gupta, G. P., Mitra, C. R., and Bhargava, K. P. (1969) Eur J Pharmacol 6, 67-70

108. Takagi, K., Park, E. H., and Kato, H. (1980) Chem Pharm Bull (Tokyo) 28, 1183-1188

109. Dai, Y., Hang, B. Q., Meng, Q. Y., Ma, S. P., and Tan, L. W. (1988) Zhongguo Yao Li Xиe Bao 9, 562-565 
110. Singh, G. B., Singh, S., Bani, S., Gupta, B. D., and Banerjee, S. K. (1992) J Pharm Pharmacol 44, 456-458

111. Niikawa, M., Hayashi, H., Sato, T., Nagase, H., and Kito, H. (1993) Mutat Res 319, $1-9$

112. Suh, N., Honda, T., Finlay, H. J., Barchowsky, A., Williams, C., Benoit, N. E., Xie, Q. W., Nathan, C., Gribble, G. W., and Sporn, M. B. (1998) Cancer Res 58, 717-723

113. Subbaramaiah, K., Michaluart, P., Sporn, M. B., and Dannenberg, A. J. (2000) Cancer Res 60, 2399-2404

114. You, H. J., Choi, C. Y., Kim, J. Y., Park, S. J., Hahm, K. S., and Jeong, H. G. (2001) FEBS Lett 509, 156-160

115. Ikeda, Y., Murakami, A., and Ohigashi, H. (2005) Biochem Pharmacol 70, 1497-1505

116. Murakami, A., Takahashi, M., Jiwajinda, S., Koshimizu, K., and Ohigashi, H. (1999) Biosci Biotechnol Biochem 63, 1811-1812

117. Sulaiman, M. R., Perimal, E. K., Akhtar, M. N., Mohamad, A. S., Khalid, M. H., Tasrip, N. A., Mokhtar, F., Zakaria, Z. A., Lajis, N. H., and Israf, D. A. (2010) Fitoterapia 81, 855-858

118. Murakami, A., Hayashi, R., Tanaka, T., Kwon, K. H., Ohigashi, H., Safitri, R., and Takana, T. (2003) Biochem Pharmacol 66, 1253-1261

119. Tanaka, T., Shimizu, M., Kohno, H., Yoshitani, S., Tsukio, Y., Murakami, A., Safitri, R., Takahashi, D., Yamamoto, K., Koshimizu, K., Ohigashi, H., and Mori, H. (2001) Life Sci 69, 1935-1945

120. Kim, M., Miyamoto, S., Yasui, Y., Oyama, T., Murakami, A., and Tanaka, T. (2009) Int J Cancer 124, 264-271

121. Murakami, A., Takahashi, D., Kinoshita, T., Koshimizu, K., Kim, H. W., Yoshihiro, A., Nakamura, Y., Jiwajinda, S., Terao, J., and Ohigashi, H. (2002) Carcinogenesis 23, 795-802

122. Murakami, A., Shigemori, T., and Ohigashi, H. (2005) J Nutr 135, 2987S-2992S

123. Xu, K., Robida, A. M., and Murphy, T. J. (2000) J Biol Chem 275, 23012-23019

124. Lasa, M., Mahtani, K. R., Finch, A., Brewer, G., Saklatvala, J., and Clark, A. R. (2000) Mol Cell Biol 20, 4265-4274

125. Rousseau, S., Morrice, N., Peggie, M., Campbell, D. G., Gaestel, M., and Cohen, P. (2002) EMBO J 21, 6505-6514

126. Subbaramaiah, K., Marmo, T. P., Dixon, D. A., and Dannenberg, A. J. (2003) J Biol Chem 278, 37637-37647

127. Nakamura, Y., Yoshida, C., Murakami, A., Ohigashi, H., Osawa, T., and Uchida, K. (2004) FEBS Lett 572, 245-250 
128. Ohnishi, K., Irie, K., and Murakami, A. (2009) Biosci Biotechnol Biochem 73, 1905-1907

129. Clarke, J. D., Dashwood, R. H., and Ho, E. (2008) Cancer Lett 269, 291-304

130. Hu, C., Eggler, A. L., Mesecar, A. D., and van Breemen, R. B. (2011) Chem Res Toxicol 24, 515-521

131. Heiss, E., Herhaus, C., Klimo, K., Bartsch, H., and Gerhäuser, C. (2001) J Biol Chem 276, 32008-32015

132. Dickinson, S. E., Melton, T. F., Olson, E. R., Zhang, J., Saboda, K., and Bowden, G. T. (2009) Cancer Res 69, 7103-7110

133. Shan, Y., Wang, X., Wang, W., He, C., and Bao, Y. (2010) Oncol Rep 23, 1133-1138

134. Chen, X. L., Dodd, G., and Kunsch, C. (2009) Inflamm Res 58, 513-521

135. Hu, R., Xu, C., Shen, G., Jain, M. R., Khor, T. O., Gopalkrishnan, A., Lin, W., Reddy, B., Chan, J. Y., and Kong, A. N. (2006) Cancer Lett 243, 170-192

136. Gan, N., Wu, Y. C., Brunet, M., Garrido, C., Chung, F. L., Dai, C., and Mi, L. (2010) J Biol Chem 285, 35528-35536

137. Jordt, S. E., Bautista, D. M., Chuang, H. H., McKemy, D. D., Zygmunt, P. M., Högestätt, E. D., Meng, I. D., and Julius, D. (2004) Nature 427, 260-265

138. Hinman, A., Chuang, H. H., Bautista, D. M., and Julius, D. (2006) Proc Natl Acad Sci USA 103, 19564-19568

139. Murakami, A. (2009) Forum Nutr 61, 193-203

140. Murakami, A., and Ohigashi, H. (2007) Int J Cancer 121, 2357-2363

141. Narukawa, M., Koizumi, K., Iwasaki, Y., Kubota, K., and Watanabe, T. (2010) Biosci Biotechnol Biochem 74, 1694-1696

142. Murakami, A., Toyota, K., Ohura, S., Koshimizu, K., and Ohigashi, H. (2000) J Agric Food Chem 48, 1518-1523

143. Bautista, D. M., Movahed, P., Hinman, A., Axelsson, H. E., Sterner, O., Högestätt, E. D., Julius, D., Jordt, S. E., and Zygmunt, P. M. (2005) Proc Natl Acad Sci U S A 102, 12248-12252

144. Hosono, T., Fukao, T., Ogihara, J., Ito, Y., Shiba, H., Seki, T., and Ariga, T. (2005) $J$ Biol Chem 280, 41487-41493

145. Andrè, E., Campi, B., Materazzi, S., Trevisani, M., Amadesi, S., Massi, D., Creminon, C., Vaksman, N., Nassini, R., Civelli, M., Baraldi, P. G., Poole, D. P., Bunnett, N. W., Geppetti, P., and Patacchini, R. (2008) J Clin Invest 118, 2574-2582

146. Yokoyama, T., Ohbuchi, T., Saito, T., Sudo, Y., Fujihara, H., Minami, K., Nagatomo, T., Uezono, Y., and Ueta, Y. (2011) Eur J Pharmacol 655, 31-37

147. Macpherson, L. J., Dubin, A. E., Evans, M. J., Marr, F., Schultz, P. G., Cravatt, B. F., 
and Patapoutian, A. (2007) Nature 445, 541-545

148. Trevisani, M., Siemens, J., Materazzi, S., Bautista, D. M., Nassini, R., Campi, B., Imamachi, N., Andrè, E., Patacchini, R., Cottrell, G. S., Gatti, R., Basbaum, A. I., Bunnett, N. W., Julius, D., and Geppetti, P. (2007) Proc Natl Acad Sci U S A 104, 13519-13524

149. Ramachandran, P. V., Yip-Schneider, M., and Schmidt, C. M. (2009) Future Med Chem 1, 179-200

150. Peng, J., and Li, Y. J. (2010) Eur J Pharmacol 627, 1-7

151. Cesare, P., Moriondo, A., Vellani, V., and McNaughton, P. A. (1999) Proc Natl Acad Sci USA 96, 7658-7663

152. Zhang, L. L., Yan Liu, D., Ma, L. Q., Luo, Z. D., Cao, T. B., Zhong, J., Yan, Z. C., Wang, L. J., Zhao, Z. G., Zhu, S. J., Schrader, M., Thilo, F., Zhu, Z. M., and Tepel, M. (2007) Circ Res 100, 1063-1070

153. Packer, L., Witt, E. H., and Tritschler, H. J. (1995) Free Radic Biol Med 19, 227-250

154. Wollen, K. A. (2010) Altern Med Rev 15, 223-244

155. Bolognesi, M. L., Minarini, A., Tumiatti, V., and Melchiorre, C. (2006) Mini Rev Med Chem 6, 1269-1274

156. Louhelainen, M., Merasto, S., Finckenberg, P., Lapatto, R., Cheng, Z. J., and Mervaala, E. M. (2006) J Hypertens 24, 947-956

157. Poh, Z. X., and Goh, K. P. (2009) Endocr Metab Immune Disord Drug Targets 9, 392-398

158. Lii, C. K., Liu, K. L., Cheng, Y. P., Lin, A. H., Chen, H. W., and Tsai, C. W. (2010) $J$ Nutr 140, 885-892

159. Elangovan, S., and Hsieh, T. C. (2008) Int J Oncol 33, 833-838

160. Fujita, H., Shiosaka, M., Ogino, T., Okimura, Y., Utsumi, T., Sato, E. F., Akagi, R., Inoue, M., Utsumi, K., and Sasaki, J. (2008) Brain Res 1206, 1-12

161. Suh, J. H., Shenvi, S. V., Dixon, B. M., Liu, H., Jaiswal, A. K., Liu, R. M., and Hagen, T. M. (2004) Proc Natl Acad Sci U S A 101, 3381-3386

162. Kawamori, T., Rao, C. V., Seibert, K., and Reddy, B. S. (1998) Cancer Res 58, 409-412 163. Steinbach, G., Lynch, P. M., Phillips, R. K., Wallace, M. H., Hawk, E., Gordon, G. B., Wakabayashi, N., Saunders, B., Shen, Y., Fujimura, T., Su, L. K., and Levin, B. (2000) N Engl J Med 342, 1946-1952

164. Pang, R. P., Zhou, J. G., Zeng, Z. R., Li, X. Y., Chen, W., Chen, M. H., and Hu, P. J. (2007) Cancer Lett 251, 268-277

165. Grösch, S., Tegeder, I., Niederberger, E., Bräutigam, L., and Geisslinger, G. (2001) FASEB J 15, 2742-2744 
166. Kulp, S. K., Yang, Y. T., Hung, C. C., Chen, K. F., Lai, J. P., Tseng, P. H., Fowble, J. W., Ward, P. J., and Chen, C. S. (2004) Cancer Res 64, 1444-1451

167. Lev-Ari, S., Kazanov, D., Liberman, E., Ben-Yosef, R., and Arber, N. (2007) Dig Dis Sci 52, 1128-1133

168. Dogné, J. M., Thiry, A., and Supuran, C. T. (2008) Curr Pharm Des 14, 679-684

169. Kashfi, K., and Rigas, B. (2005) Biochem Pharmacol 70, 969-986

170. Shanware, N. P., Williams, L. M., Bowler, M. J., and Tibbetts, R. S. (2009) BMB Rep 42, $142-147$

171. Xie, L., Li, J., and Bourne, P. E. (2009) PLoS Comput Biol 5, e1000387

172. Chavez, J., Chung, W. G., Miranda, C. L., Singhal, M., Stevens, J. F., and Maier, C. S. (2010) Chem Res Toxicol 23, 37-47

173. Ganesan, L., Margolles-Clark, E., Song, Y., and Buchwald, P. (2011) Biochem Pharmacol 81, 810-818

174. Zhang, Y., Lukacova, V., Reindl, K., and Balaz, S. (2006) J Biochem Biophys Methods 67, $107-122$

175. McLure, J. A., Birkett, D. J., Elliot, D. J., Williams, J. A., Rowland, A., and Miners, J. O. (2011) Drug Metab Dispos

176. Lambert, J. D., Sang, S., and Yang, C. S. (2007) Mol Pharm 4, 819-825

177. Manach, C., Williamson, G., Morand, C., Scalbert, A., and Rémésy, C. (2005) Am J Clin Nutr 81, 230S-242S

178. Williamson, G., and Manach, C. (2005) Am J Clin Nutr 81, 243S-255S

179. Wu, Q., Dohnal, V., Huang, L., Kuča, K., Wang, X., Chen, G., and Yuan, Z. (2011) Curr Drug Metab 12, 1-10

180. Mally, A., Keim-Heusler, H., Amberg, A., Kurz, M., Zepnik, H., Mantle, P., Völkel, W., Hard, G. C., and Dekant, W. (2005) Toxicol Appl Pharmacol 206, 43-53

181. Hundal, H. S., and Taylor, P. M. (2009) Am J Physiol Endocrinol Metab 296, E603-613

182. Bryant, N. J., Govers, R., and James, D. E. (2002) Nat Rev Mol Cell Biol 3, 267-277

183. Pike, N. B., and Wise, A. (2004) Curr Opin Investig Drugs 5, 271-275

184. Kaempf-Rotzoll, D. E., Traber, M. G., and Arai, H. (2003) Curr Opin Lipidol 14, 249-254

185. Ba, J., and Friedman, P. A. (2004) Cell Calcium 35, 229-237

186. Sekler, I., Sensi, S. L., Hershfinkel, M., and Silverman, W. F. (2007) Mol Med 13, 337-343

187. Son, T. G., Camandola, S., and Mattson, M. P. (2008) Neuromolecular Med 10, 236-246 
188. Bukowski, J. A., and Lewis, R. J. (2000) South Med J93, 371-374

189. Lands, W. E. (1998) Alcohol 15, 147-160

190. Mattson, M. P. (2008) Ageing Res Rev 7, 43-48

191. Radak, Z., Chung, H. Y., Koltai, E., Taylor, A. W., and Goto, S. (2008) Ageing Res Rev 7, 34-42

192. Hirota, A., Kawachi, Y., Yamamoto, M., Koga, T., Hamada, K., and Otsuka, F. (2011) Exp Dermatol 20, 664-668

193. Tempfer, C. B., Froese, G., Heinze, G., Bentz, E. K., Hefler, L. A., and Huber, J. C. (2009) Am J Med 122, 939-946.e939

194. Yellapu, R. K., Mittal, V., Grewal, P., Fiel, M., and Schiano, T. (2011) Can J Gastroenterol 25, 157-160

195. Sauer, J., Mason, J. B., and Choi, S. W. (2009) Curr Opin Clin Nutr Metab Care 12, 30-36 


\section{Figure legends}

\section{Figure 1}

Differences in general research directions between pharmacology and food science.

\section{Figure 2}

Chemical structures of phytochemicals referred to in this manuscript. EGCg, (-)-epigallocatechin-3-gallate; UA, ursolic acid; OA, oleanolic acid; DATS, diallyl trisulfide; LA, $\alpha$-lipoic acid.

\section{Figure 3}

Brief scheme of generalized signal transduction pathways.

\section{Figure 4}

A. Chemical structures of phenol, catechol, and pyrogallol. B. Superoxide anion generation from catechol.

\section{Figure 5}

Action mechanism underlying Nrf2 activation following oxidative and electrophilic stresses. In a normal state, the transcription factor Nrf2 is continuously ubiquitinated by the Cul3-Keap1 ubiquitin E3 ligase complex and thereby rapidly subjected to degradation in proteasomes. Electrophilic chemicals and oxidative stresses oxidize the reactive cysteine residues of Keap1 for reducing the E3 ligase activity. This critical step stabilizes Nrf2 and thereby induces robust expression of a battery of cytoprotective genes. Prior to translocation of Nrf2 into the nucleus, its transcription activity is modulated by several protein kinases, which are simultaneously activated by stimuli.

\section{Figure 6}

Antioxidant system based on glutathione (GSH), thioredoxin (Trx), and 
peroxiredoxins (Prx). Trx acts as a redox sensor protein that is highly susceptible to oxidative stress to form intra-molecular disulfide bonds, thereby reducing oxidized, client proteins. Peroxiredoxins (Prxs), which are highly expressed in various cellular compartments, comprise a peroxidase family that reduces intracellular peroxides with the Trx system as the electron donor.

\section{Figure 7}

Proposed molecular mechanisms by which UA induces pro-inflammatory cytokines in murine M $\phi$. Aggregated UA is recognized by CD36 and then ROS are intracellularly generated, presumably by NOX. This process triggers the activation of MAPK pathways and $\mathrm{NF \kappa B}$ for promoting transcription of pro-inflammatory mediator (such as iNOS, TNF- $\alpha$, and IL-1 $\beta$ ) genes, leading to the expression of pro-inflammatory mediators for intracellular protein production. Then, intracellular proteins are released and exhibit biological functions.

\section{Figure 8}

A. Protein cysteine thiol has potential to make an adduct with zerumbone via nucleophilic addition. B. Preparation method of Sepharose zerumbone. ECH Sepharose $4 \mathrm{~B}$ reacts with a bromine-derivative of zerumbone under a strong alkaline condition.

\section{Figure 9}

Plants are exposed to severe environmental stresses that induce them to biosynthesize secondary metabolites such as antioxidants, antifeedants, antibiotics, and others. Without those reactions, they will be exterminated by the stressors.

\section{Figure 10}

General scheme of stress adaptation. Environmental stress has a potential to strength the adaptation system, allowing the host to acquire stronger resistance 
to harsher stresses. However, when the stress exceeds the defense capacity, it becomes toxic and occasionally lethal. 


\section{Pharmacology}

Drug design Rational synthesis (Molecular target already known)

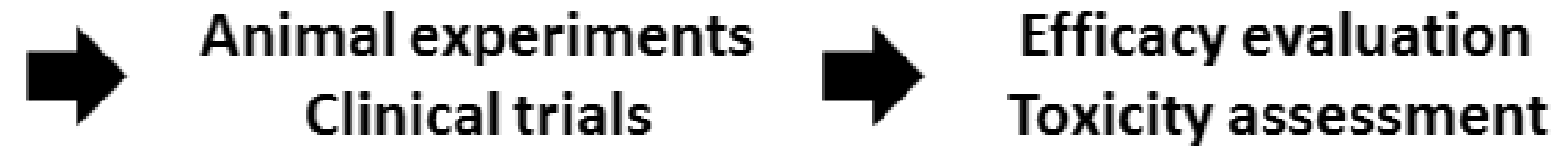

\section{Food science}

Cellular \& animal experiments 


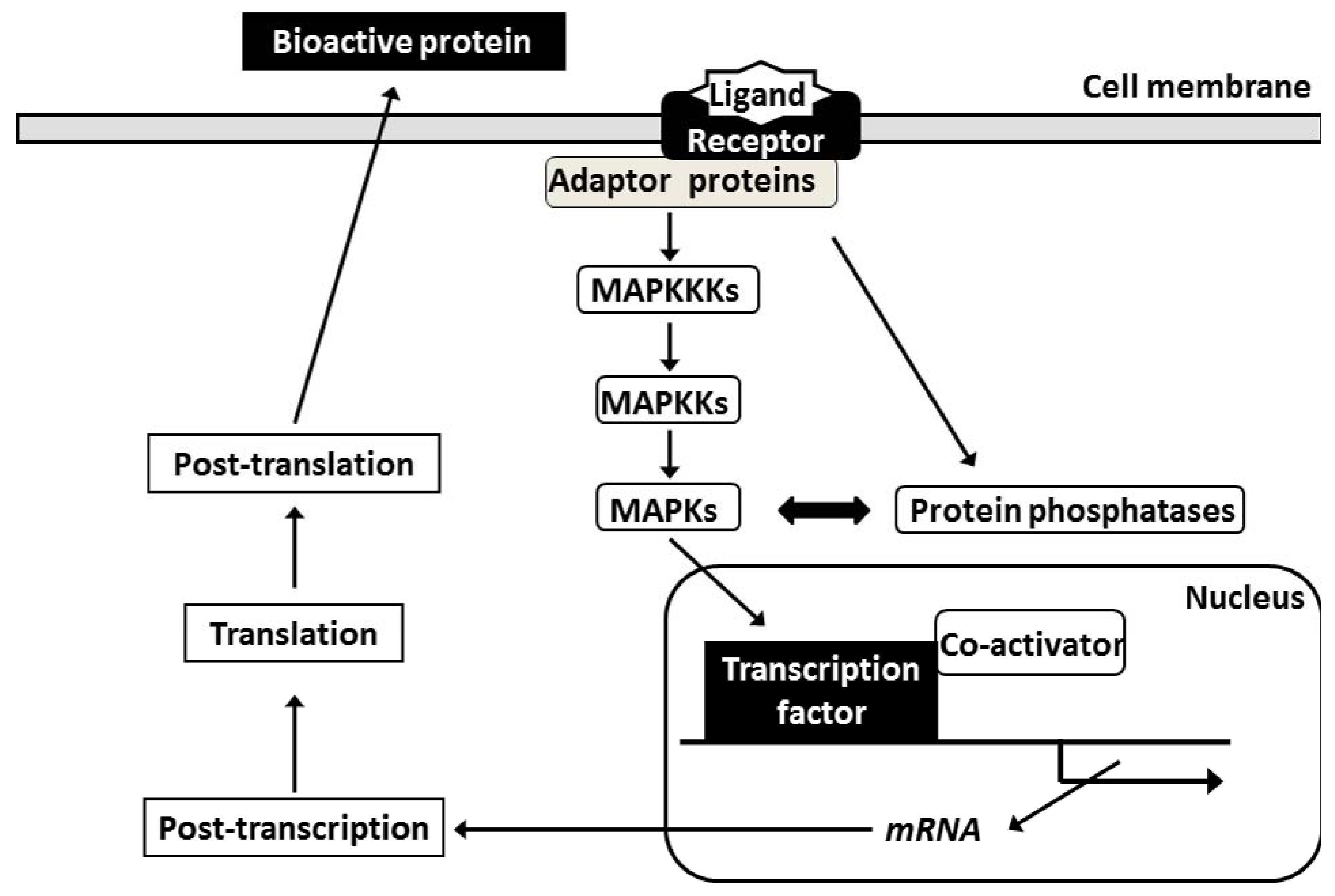

Figure 3. Murakami et al. 
A

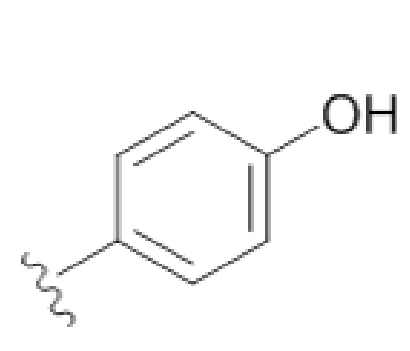

Phenol

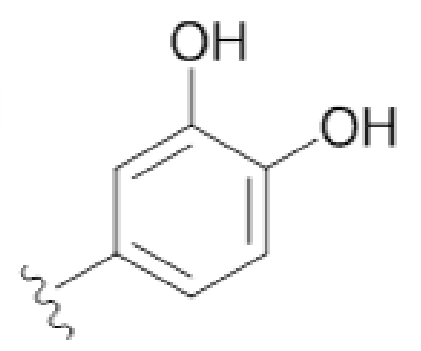

Catechol

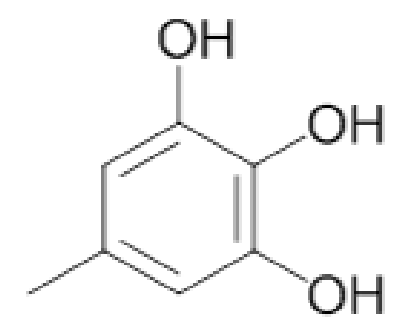

Pyrogallol

B

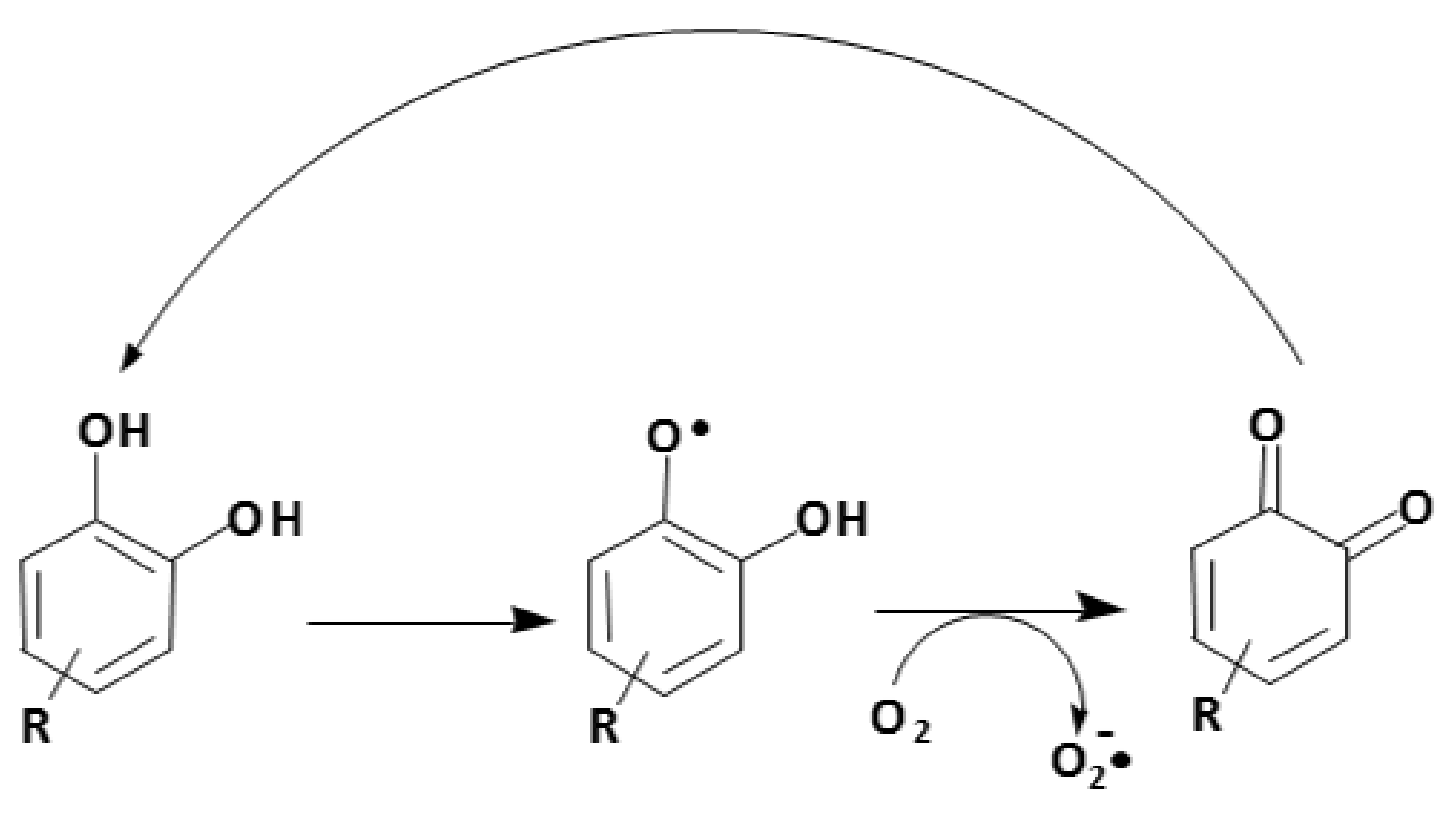



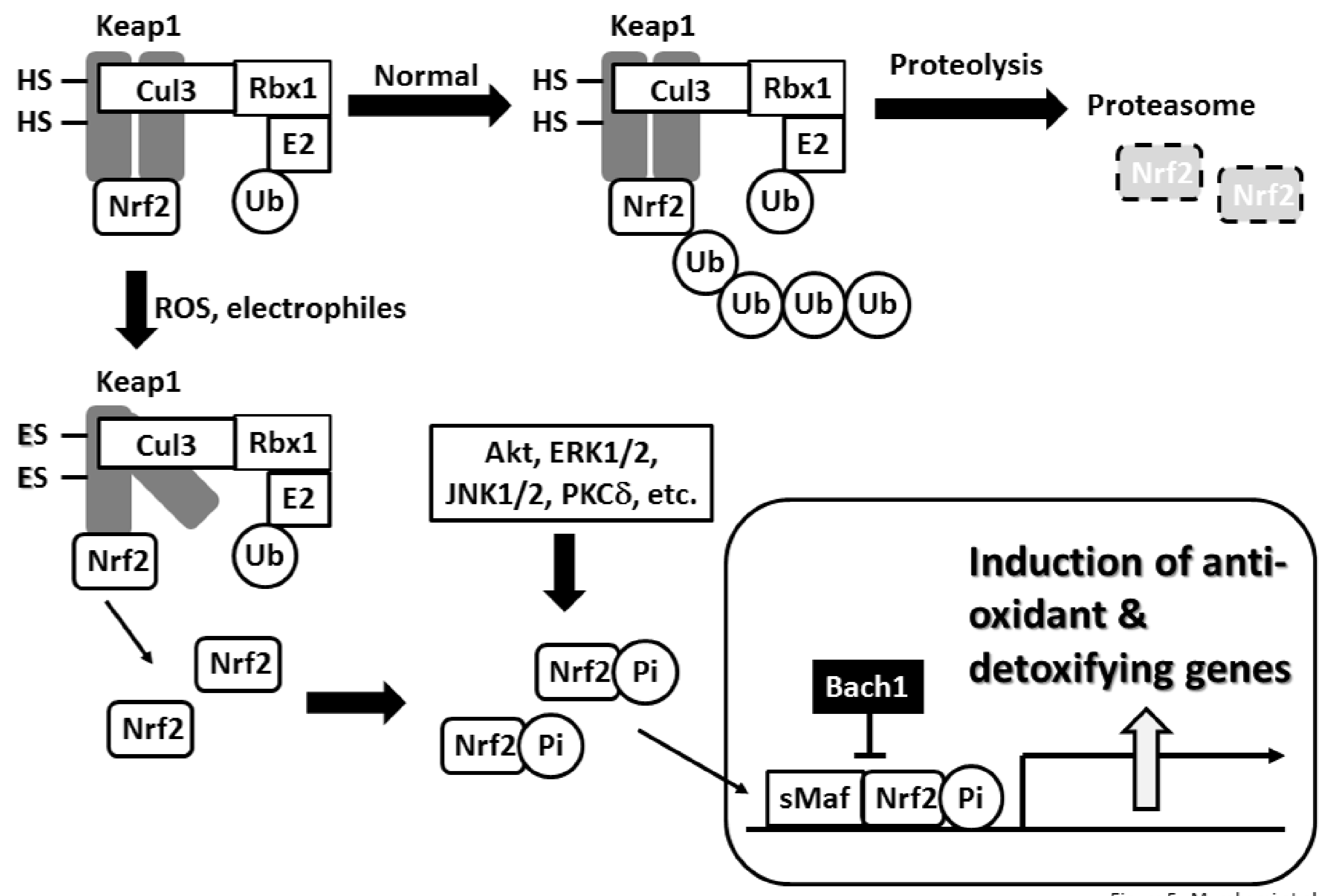


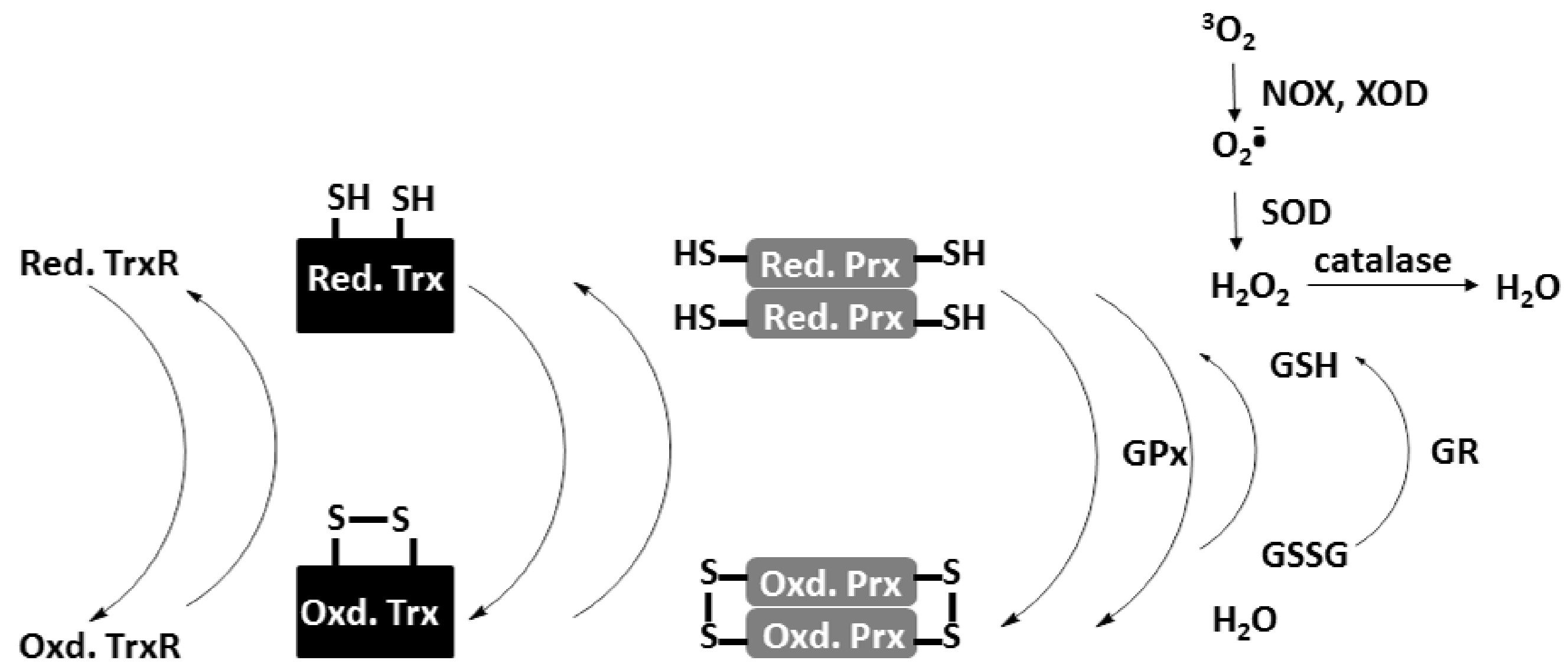




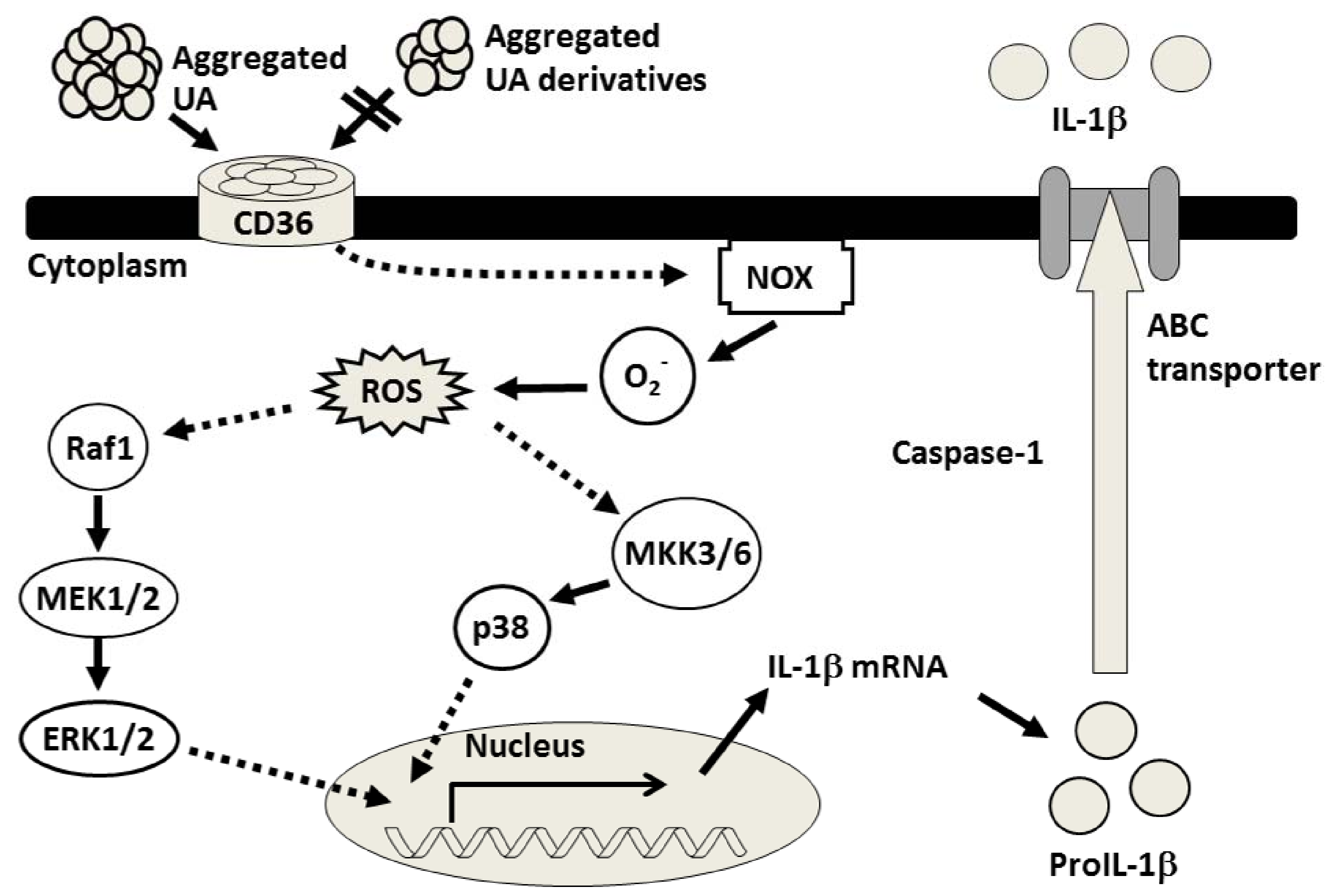


A
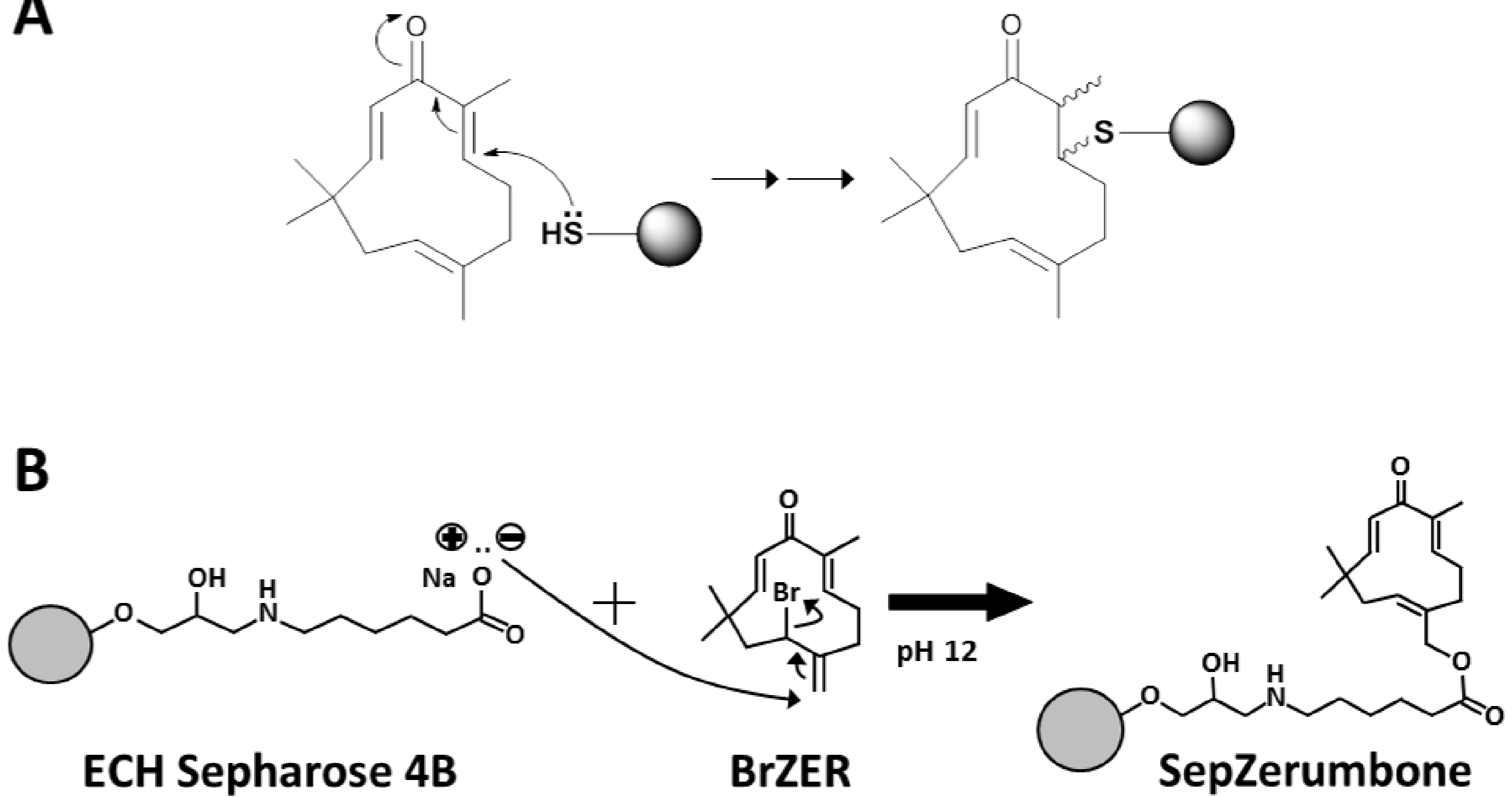


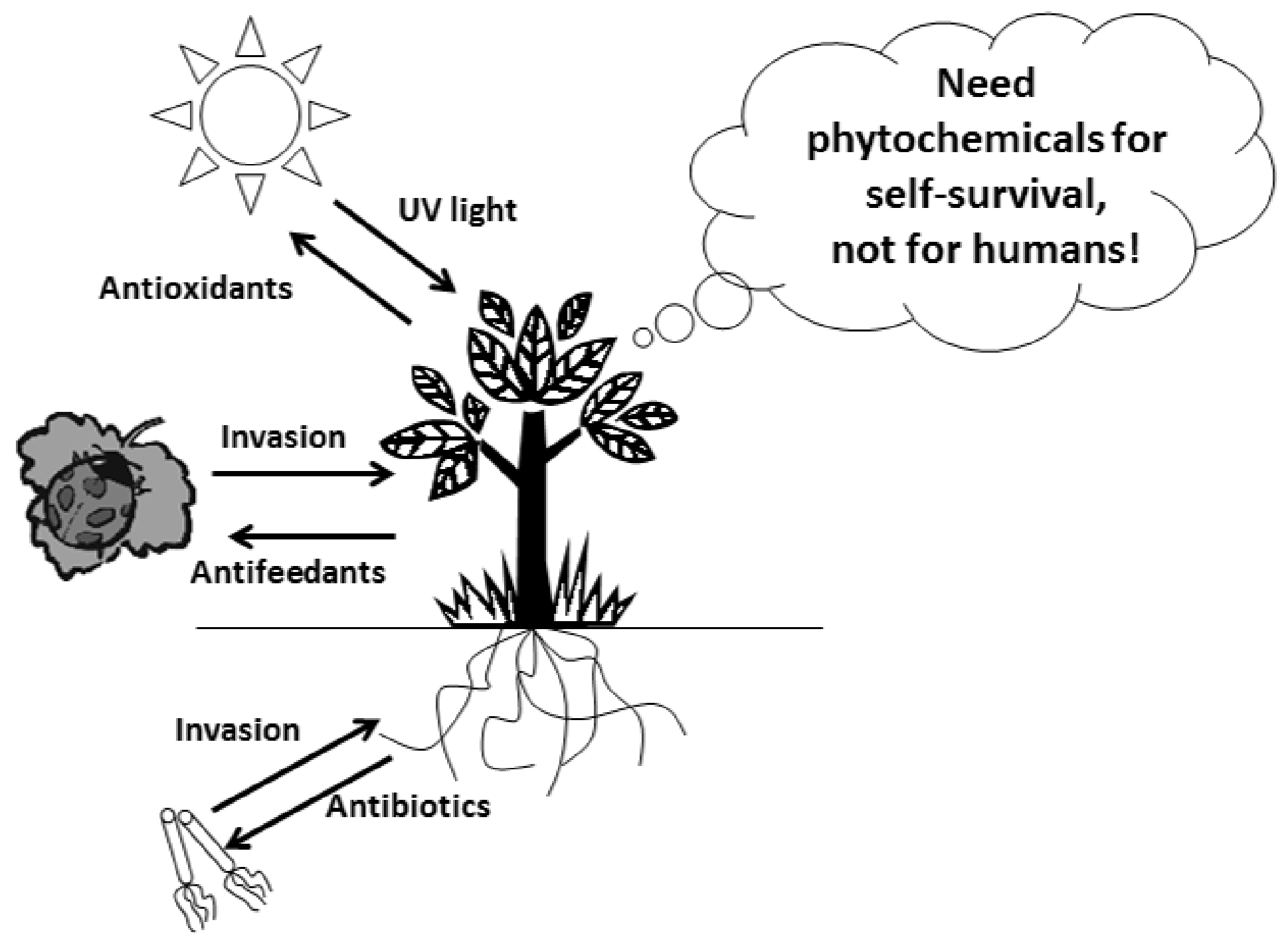




\section{Adaptation}

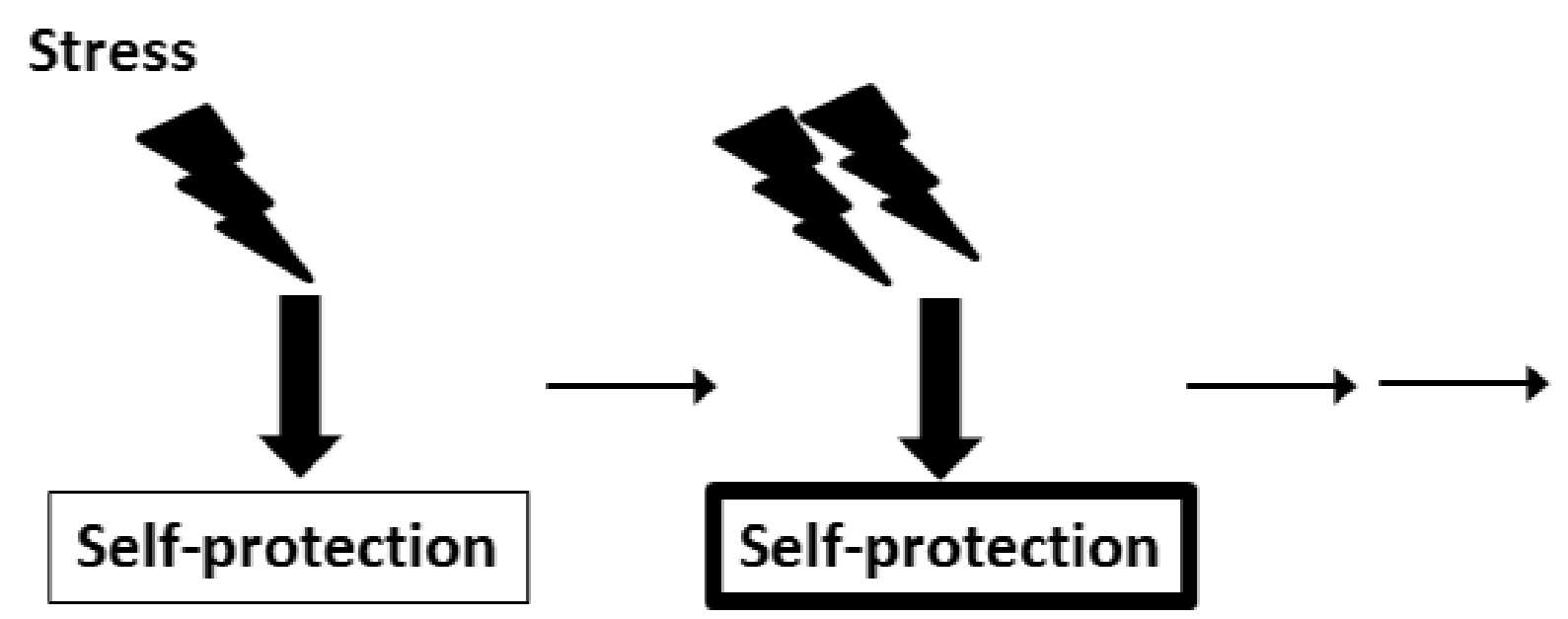

\section{Catastrophe}

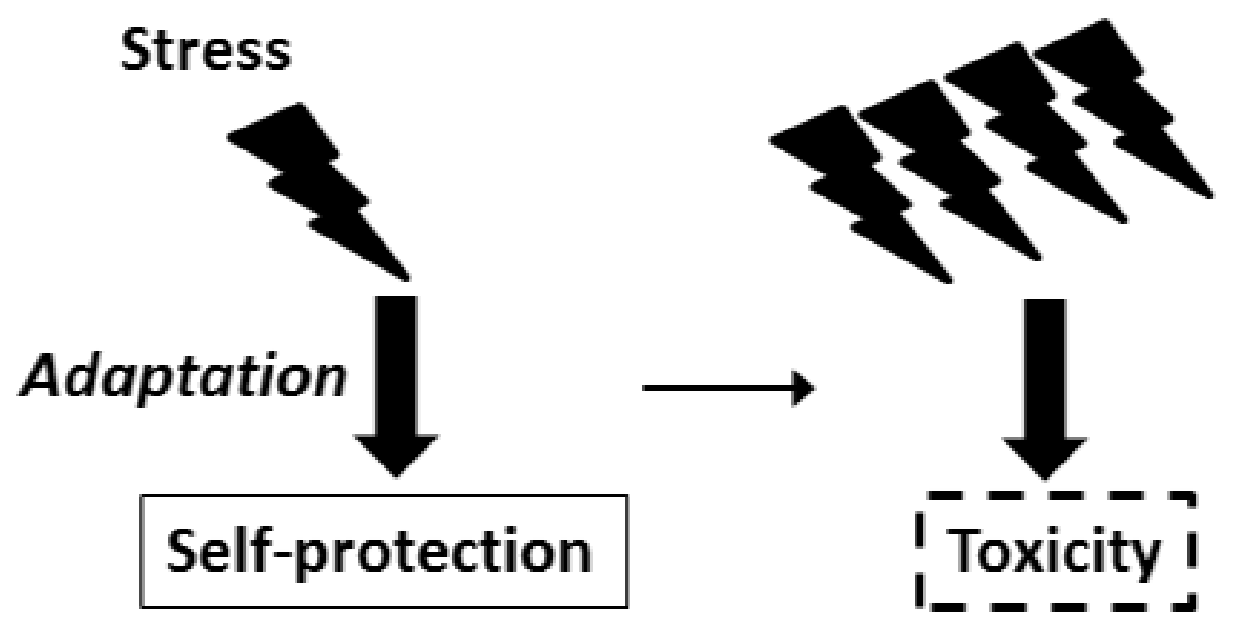

